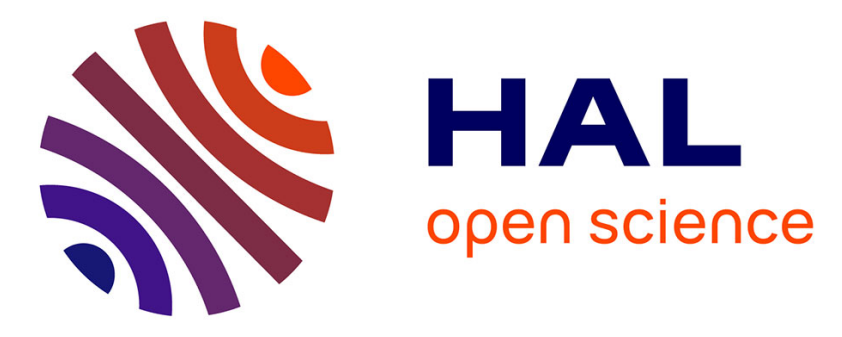

\title{
Mesoscale analysis of damage growth in woven composites
}

Aurélien Doitrand, Christian Fagiano, François Hild, Vincent Chiaruttini, Anne Mavel, Martin Hirsekorn

\section{- To cite this version:}

Aurélien Doitrand, Christian Fagiano, François Hild, Vincent Chiaruttini, Anne Mavel, et al.. Mesoscale analysis of damage growth in woven composites. Composites Part A: Applied Science and Manufacturing, 2017, 96, pp.77-88. 10.1016/j.compositesa.2017.02.018 . hal-01480982

\section{HAL Id: hal-01480982 \\ https://hal.science/hal-01480982}

Submitted on 2 Mar 2017

HAL is a multi-disciplinary open access archive for the deposit and dissemination of scientific research documents, whether they are published or not. The documents may come from teaching and research institutions in France or abroad, or from public or private research centers.
L'archive ouverte pluridisciplinaire HAL, est destinée au dépôt et à la diffusion de documents scientifiques de niveau recherche, publiés ou non, émanant des établissements d'enseignement et de recherche français ou étrangers, des laboratoires publics ou privés. 


\title{
Mesoscale analysis of damage growth in woven composites
}

\author{
Aurélien Doitrand ${ }^{a, 1}$, Christian Fagiano ${ }^{a}$, François $\operatorname{Hild}^{b}$, Vincent Chiaruttini $^{a}$, Anne Mavel ${ }^{a}$, \\ Martin Hirsekorn ${ }^{a}$ \\ ${ }^{a}$ ONERA, The French Aerospace Lab, 29 avenue de la Division Leclerc, F-92320 Châtillon, France \\ ${ }^{b}$ LMT, ENS Paris-Saclay / CNRS / University Paris-Saclay, 61 avenue du Président Wilson, F-94235 \\ Cachan Cedex, France
}

\begin{abstract}
The characteristic damage mechanisms of a four-layer plain weave glass fiber/epoxy matrix composite are analyzed by means of optical microscope observations on the edge of a rectangular specimen under tensile loading. Digital image correlation is used to determine the size of transverse yarn cracks and yarn-yarn debonding around the crack tips. An algorithm based on Finite Fracture Mechanics is proposed to model crack and debond initiation and propagation in the composite, which takes into account possible couplings between the cracks. The predicted debond and crack densities are in good agreement with the experimental observations.

Keywords: B. Transverse cracking; B. Debonding ; C. Damage mechanics; C. Finite element analysis (FEA)
\end{abstract}

\section{Introduction}

Woven composites are increasingly used for lightweight aeronautical and automotive applications. The large variety in the choice of the reinforcing fabric allows the number of assembly operations to be reduced, which results in fewer weak points in a structure and lower production costs.

The behavior of woven composites may be optimized using design tools able to describe the change in their mechanical behavior from damage initiation to failure. Currently, design methods are based on macroscopic models predicting damage growth and failure in $2 \mathrm{D}[1,2]$

\footnotetext{
${ }^{1}$ Corresponding author Email address: aurelien.doitrand@onera.fr (Aurélien Doitrand)
} 
and $3 \mathrm{D}[3,4,5,6,7]$ woven composites. These models require time consuming and expensive experimental tests in order to calibrate their parameters. Moreover, the model parameters must be recalibrated each time the constituents or the fiber architecture change. The number of tests may be reduced if some of the parameters can be determined by simulation of virtual tests with explicit modeling of damage initiation and propagation at the mesoscopic scale, at which the architecture of the fiber reinforcement architecture is defined.

Several strategies have been introduced to model damage at the mesoscopic scale. Gao et al. [8] proposed an analytical damage model using a mosaic laminate representation of the composite. This model allows for the calculation of the Young's modulus of the damaged composite. However, yarn undulation, which has a major influence on damage location [9, 10], is neglected. Damage in woven composites at the mesoscopic scale is generally modeled using Finite Element (FE) approaches based on Continuum Damage Mechanics (CDM) [9, $10,11,12]$. One drawback of such models is an erroneous prediction of damage propagation directions $[12,13]$. Moreover, these models require regularization methods in order to avoid damage pattern dependence on the FE mesh $[14,15]$, and very fine meshes in order to obtain a good representation of localized cracks observed experimentally [16, 17, 18, 19]. Localized cracks can be modeled more accurately using discrete damage models [19, 20, 21, 22], which consist in directly inserting cracks in the FE mesh.

The modeling of damage growth requires tools that are able to determine damage initiation and propagation within the composite. Damage initiation in woven composites is generally modeled using a stress-based criterion [9, 10, 11, 12, 19, 23], which gives a good estimate of the crack locations $[19,23,24]$. However, the damage initiation strain is underestimated if only a stress criterion is used and a better estimate is obtained [24] if energetic considerations based on Finite Fracture Mechanics (FFM) [31] are also taken into account, as proposed by Leguillon [32], for instance. In a previous work [24], it has been shown that, in the studied composite, the energy criterion is dominant and thus Finite Fracture Mechanics can be used to accurately model the initiation of yarn cracks. Moreover, it also allows for the determination of the crack initiation configuration (e.g., length, orientation). The propagation of existing cracks 
in quasi-brittle materials can also be modeled using Fracture Mechanics. Yet, to the authors' knowledge, damage propagation in woven composites has mainly been studied using models based on CDM $[9,10,11,12]$.

In this work, Finite Fracture Mechanics is followed to model damage growth in a composite consisting of four layers of glass fiber plain weave and epoxy matrix. In Section 2, optical micrographs of yarn cracks and debonding are presented. The crack and debond lengths are determined by means of digital image correlation (DIC). The algorithm developed to assess damage propagation is summarized in Section 3. It is used in Section 4 to determine the propagation of multiple cracks taking into account the possible coupling between several cracks. A comparison of the predicted damage growth to the experimental observations is presented in Section 5 .

\section{Digital image correlation for damage detection}

\subsection{Material and testing}

The composite under investigation was manufactured at Onera and consists of four layers of E-glass fiber plain weave reinforcement embedded in Araldite LY564/Hardener XB 3487 epoxy matrix. The plain fabric thread count is $2.2 \mathrm{warps} / \mathrm{cm} \times 2 \mathrm{wefts} / \mathrm{cm}$. The fabric mass per unit area is $504 \pm 40 \mathrm{~g} / \mathrm{m}^{2}$, the linear density of the yarns is 1200 TEX and the mass density of the fibers is $2.54 \mathrm{~g} / \mathrm{cm}^{3}$. The dry fabric was compacted in a steel mold before matrix injection, which results in a mean fiber volume fraction in the composite of $47 \%$. A parallelepipedic specimen was tested under incremental tensile loading in order to quantify damage using optical microscopy focused on the edge of the specimen at four strain levels, as well as Young's modulus and Poisson's ratio changes using stereo-DIC [19]. Acoustic Emission (AE) was also used in order to determine the damage initiation strain. The damage mechanisms observed experimentally follow the microstructure of the composite (Figure 1(a) and (b)). Transverse yarn cracks and debonding between yarns around the crack tip are observed (Figure 1(b)).

The damage analysis requires the calculation of crack and debond densities inside the material. The crack (resp. debond) density is defined as the ratio between the total crack (resp. 
debond) surfaces and the volume of the observed zone. Since optical microscopy only provide a surface measurement of crack and debond lengths on the specimen edge, the crack (resp. debond) density $\rho_{c}^{\text {exp }}$ (resp. $\rho_{\mu}^{e x p}$ ) obtained experimentally is calculated as a function of the number of cracks $N_{\text {cracks }}$, the crack (resp. debond) lengths $\ell_{k}^{c}\left(\right.$ resp. $\left.\ell_{k}^{\mu}\right)$ and the height $h$ and length $L$ of the observed zone

$$
\left\{\begin{array}{l}
\rho_{c}^{e x p}=\sum_{k=1}^{N_{\text {cracks }}} \frac{\ell_{k}^{c}}{L h} \\
\rho_{\mu}^{\text {exp }}=\sum_{k=1}^{N_{\text {cracks }}} \frac{\ell_{k}^{\mu}}{L h}
\end{array}\right.
$$

Gao et al. [25] showed that the crack densities measured inside and on the edge of a woven composite were similar. This is confirmed for the studied material by transmitted light observations on the tested specimen (see Figure 1(a)), which show that the crack densities on the edge and in the central part of the specimen are qualitatively similar. Therefore, it seems reasonable to assume that the crack and debond densities calculated in Equation (1) are representative of the whole material.

\subsection{Damage detection}

Intra-yarn cracks can generally be easily identified via optical micrographs on the specimen edge since most of them are orthogonal to the loading direction (Figure 1b) and therefore open under tension. However, it is more difficult to detect small cracks or debonding that are almost parallel to the loading directions (Figure 1b). Therefore, digital image correlation between a state without damage and a cracked state is used to detect cracks [26, 27]. In this work, a mechanically regularized global DIC method [28] is used. The main advantage of this method compared to classical local DIC is its ability to detect displacement discontinuities due to the presence of a crack by taking into account a mechanical regularization. The method consists in defining a mesh on the reference image and determining a displacement field, $\mathbf{u}$, defined at 
each node of the mesh, that minimizes the functional $\Phi_{t}$ over the region of interest (ROI)

$$
\left\{\begin{array}{l}
\left(1+w_{m}+w_{b}\right) \Phi_{t}^{2}=\tilde{\Phi}_{c}^{2}+w_{m} \tilde{\Phi}_{m}^{2}+w_{b} \tilde{\Phi}_{b}^{2} \\
\tilde{\Phi}_{c}=\frac{\Phi_{c}(\mathbf{u})}{\Phi_{c}(\mathbf{v})}, \tilde{\Phi}_{m}=\frac{\Phi_{m}(\{\mathbf{u}\})}{\Phi_{m}(\{\mathbf{v}\})}, \tilde{\Phi}_{b}=\frac{\Phi_{b}(\{\mathbf{u}\})}{\Phi_{b}(\{\mathbf{v}\})} \\
\Phi_{c}^{2}(\mathbf{u})=\sum_{\mathrm{ROI}} \varphi_{c}^{2}(\mathbf{x})=\sum_{\mathrm{ROI}}(f(\mathbf{x})-g(\mathbf{x}+\mathbf{u}(\mathbf{x})))^{2} \\
\Phi_{m}^{2}(\{\mathbf{u}\})=\{\mathbf{u}\}^{t}[\mathbf{K}]^{t}[\mathbf{K}]\{\mathbf{u}\} \\
\Phi_{b}^{2}(\{\mathbf{u}\})=\{\mathbf{u}\}^{t}[\mathbf{L}]^{t}[\mathbf{L}]\{\mathbf{u}\}
\end{array}\right.
$$

where $f$ and $g$ are, respectively, the gray levels of the pictures in the reference and deformed configurations, $\mathbf{x}$ any pixel location, $\{\mathbf{u}\}$ the column vector gathering all nodal displacements, $[\mathbf{K}]$ the (rectangular) stiffness matrix associated with the inner nodes, and $[\mathbf{L}]$ an operator acting on the boundary nodes. The normalized functionals are based on a trial displacement field, $\mathbf{v}$, which is chosen as a plane wave [28]. The weights $w_{m}$ and $w_{b}$ are directly linked to the regularization lengths $\ell_{m}$ and $\ell_{b}$, which weigh each term of the functional $\Phi_{t} . \varphi_{c}$ is called the correlation residual field, which highlights the differences between the reference and the deformed pictures corrected by the measured displacement field $\mathbf{u}$ (e.g., cracks and debonding). Before the test, and for each strain level, 27 micrographs have been acquired on the visible area of the specimen edge. The DIC method is used to obtain the correlation residuals for the 27 areas using a mesh composed of 3-noded triangles whose characteristic edge length is 20 pixels (the size of the region of interest in each area is about $650 \times 1000$ pixels), resulting in about 2,500 degrees of freedom. The regularization lengths are $\ell_{m}=2 \ell_{b}=64$ pixels. This choice results from a compromise between the spatial resolution and the measurement uncertainty. The correlation residuals obtained for the area outlined in black in Figure 1(b) are shown in Figure 1(c). The crack and debond lengths on the edge of the specimen are measured manually using the correlation residuals. 


\section{Algorithm for damage propagation in the representative unit cell}

\subsection{Crack propagation}

Linear elastic fracture mechanics (LEFM) describes the propagation of cracks in (brittle) elastic materials. Brittle means in this case that the plastic zone around the crack tip is much smaller than the characteristic length of the material [29]. For the material under investigation, plastic deformation of the matrix in the yarns is only visible between the fibers at the microscopic scale. The size of the plastic zone is thus of only a few micrometers. Therefore, LEFM can be used for the crack propagation analysis at the mesoscopic scale in the studied material. The proposed approach, which is used to determine crack and debonding propagation in the composite, is based on Griffith's theory [30], assuming that a crack can propagate if the potential energy release due to crack propagation is at least equal to the energy required to extend the surface of the crack

$$
\delta W_{p}+\delta W_{k}+G^{c} \delta S=0
$$

where $\delta W_{p}$ and $\delta W_{k}$ are, respectively, the potential and kinetic energy variations. The surface of the new crack is $\delta S$, and $G^{c}$ the critical energy release rate of the material. A static state before crack propagation means that $\delta W_{k}>0$, which leads to a necessary condition for crack propagation

$$
-\frac{\delta W_{p}}{\delta S} \geq G^{c}
$$

For continuous crack growth, the condition given in Equation (4) holds for any surface increment $\delta S$. The differential form of Equation (4) is obtained when $\delta S$ tends to 0

$$
-\frac{\partial W_{p}}{\partial S}=G \geq G^{c}
$$

where $G$ is the differential energy release rate. The propagation criterion established by Griffith consists in comparing $G$ to the critical energy release rate $G^{c}$. If $G<G^{c}$, the crack does not 
propagate. For a quasi-static problem, the condition for stable propagation is given by

$$
G=G^{c} \text { and } \frac{d G}{d S}<0
$$

In particular, crack propagation is stable if the crack does not propagate without any increase in prescribed strain. For a quasi-static problem, the condition for unstable propagation reads

$$
G>G^{c} \text { or }\left(G=G^{c} \text { and } \frac{d G}{d S}>0\right)
$$

Griffith's theory is adapted to study the propagation of an existing crack, but cannot be used to predict crack initiation. In the studied composite material, the initiation of transverse yarn cracks is quasi-instantaneous, which means that the time needed for a crack to initiate over a finite length is very small compared to the other timescales involved in the problem (e.g., characteristic loading time). The hypothesis that the cracks initiate instantaneously on a finite length is a good approximation. Therefore, crack initiation can be determined using coupled stress and energy criteria [32]. The method consists in finding the crack initiation configuration that fulfils both stress and energy criteria and minimizes the crack initiation strain. The stress criterion must be fulfilled over the whole surface of the crack in the undamaged material, while the energy condition states that the energy released by crack initiation must be at least equal to $G^{c} \Delta S$, which is required to open the crack of surface $\Delta S$.

The coupled criterion was used to model the initiation of transverse yarn cracks in the same material as studied herein. It was found that for the composite under investigation, the energy criterion is dominant [24]. Thus, FFM can be used. FFM is based on the assumption that damage does not grow continuously but by finite increments. In that case, the differential energy release rate is replaced by the incremental energy release rate in the condition given in 
Equation (5)

$$
\left\{\begin{array}{l}
G^{i n c}\left(S_{0}, S\right)=\frac{1}{\Delta S} \int_{S_{0}}^{S} G(\widetilde{S}) d \widetilde{S} \\
\frac{d\left(G^{i n c}\left(S_{0}, S\right) \Delta S\right)}{d S}=\frac{d G^{i n c}\left(S_{0}, S\right)}{d S} \Delta S+G^{i n c}\left(S_{0}, S\right)=G(S) \\
\Delta S=S-S_{0}
\end{array}\right.
$$

If $\frac{d G^{i n c}}{d S}<0$, the differential energy release rate is lower than the incremental one, and viceversa. If the incremental energy release rate reaches an extremum, both energy release rates are equal (since $\left.\frac{d G^{i n c}}{d S}=0\right)$.

The study of crack propagation in composites requires the calculation of the differential energy release rate and its derivative. In the complex 3D case of woven composites, this step requires FE calculations. The energy release rate can be computed using a local approach such as, e.g., the so-called G- $\theta$ method $[33,34,35]$. In that case, the simulation of the energy release rate is based on the local stress distribution in the vicinity of the crack front and requires very fine meshes. Another possibility consists in making an energy balance between the states before and after propagation for a small crack surface increment. For an infinitesimally small crack surface increment (i.e., when $\Delta S \rightarrow 0$ ), the differential and the incremental energy release rates are equal (see Equation (9)). Therefore, crack propagation can be evaluated by computing the incremental energy release rate for small crack surface increments

$$
\lim _{\Delta S \rightarrow 0} G^{i n c}\left(S_{0}, S\right)=G\left(S_{0}\right)
$$

\subsection{Propagation algorithm}

In this section, an algorithm able to predict crack propagation in the composite is presented. As explained in the previous section, the energy release rate is computed by calculating the incremental energy release rate for small crack surface increments. The objective of the proposed algorithm is to determine the change in the set of parameters describing the crack shape $d=\left(d_{1}, \ldots, d_{n}\right)$ as functions of the increasing strain level $\epsilon$. Figure 2 shows the flowchart of the algorithm:

- If damage has fully propagated (for example when a crack has crossed the whole yarn), 
the algorithm stops.

- Otherwise, if the condition $G \geq G^{c}$ is fulfilled, crack propagation is determined by the parameter $d_{i}$ whose variation $\delta_{i}$, which is defined in Figure 2, maximizes the energy release rate. If not, the strain level is increased.

- The current configuration $(d, \epsilon)$ is updated

The proposed algorithm deals with both stable and unstable crack propagation:

- Stable propagation

It has been shown that, for the composite under investigation, the incremental energy release rate of an intra-yarn crack has a maximum level [24]. The crack initiation configuration corresponds to this maximum level at $S=S^{*}$ (see Figure 3, which shows the change of $G$ and $G^{i n c}$ as functions of $S$ ). At this maximum, the incremental and differential energy release rates are equal, as shown in the previous section, and the derivative of the differential energy release rate is negative. Therefore, the condition given in Equation (6) is fulfilled and crack propagation is stable. If the derivative of the differential energy release rate remains negative for $S>S^{*}$, the propagation remains stable. If the differential energy release rate increases again for $S>S^{*}$, crack propagation may become unstable.

- Unstable propagation

The change in the differential and incremental energy release rates in case of unstable propagation is shown in Figure $3(\mathrm{~b}-\mathrm{c})$. The propagation of a crack of area $S^{*}$ is unstable since the condition given in Equation (7) is fulfilled. Therefore, the crack can propagate without any increase in the strain level. The crack propagates at least up to an area $S^{*}+\Delta S^{\text {min }}$ satisfying $G\left(S^{*}+\Delta S^{\min }\right)=G^{c}$. During crack propagation from $S=S^{*}$ to $S=S^{*}+\Delta S^{\text {min }}$, the released potential energy is higher than that required for the generation of additional crack surface $\left(G>G^{c}\right)$. This energy surplus is available for further crack propagation $[29,36]$. If this energy surplus is dissipated (i.e., not used for 
further crack propagation), the crack only propagates up to $S^{*}+\Delta S^{m i n}$. Conversely, if the energy surplus is fully used for further crack propagation, the crack can propagate up to $S^{*}+\Delta S^{\max }$ with the condition

$$
A_{1}=\int_{S^{*}}^{S *+\Delta S^{\min }}\left(G(S)-G^{c}\right) d S=\int_{S_{*+\Delta} S^{\min }}^{S_{*+\Delta S^{\max }}}\left(G^{c}-G(S)\right) d S=A_{2}
$$

If the differential energy release rate increases again after having reached a minimum level so that $G \geq G^{c}$ for $S \geq S^{*}+\Delta S^{\max }$, then, a sufficiently high energy surplus may lead to a jump over a region for which $G<G^{c}$ and the crack keeps propagating in an unstable manner (Figure 3(c)). If the energy surplus is not high enough to allow for further crack growth, the crack propagates, at most, up to $S=S^{*}+\Delta S^{\max }$, for which $A_{1}=A_{2}$ and $G\left(S^{*}+\Delta S^{\max }\right)<G^{c}$ (see Figure $\left.3(\mathrm{~b})\right)$. Then, the crack does not propagate unless applying a strain increase $\Delta \epsilon$ for which $G\left(\epsilon+\Delta \epsilon, S^{*}+\Delta S^{\max }\right)=G^{c}$.

In practice, a part of the energy surplus is used for crack propagation whereas the rest is dissipated [29]. Since it is difficult to quantify experimentally the part of the energy that is dissipated, the two extreme cases are studied in this work, i.e., without or with complete dissipation of the energy surplus.

\subsection{Discrete damage modeling in a realistic representative unit cell}

The propagation algorithm presented in the previous section requires the calculation of the incremental energy release rate of a crack. Therefore, a geometrical representation and an FE mesh of the composite including a good representation of the yarn volume fraction and of the local strain/stress fields are required for an accurate determination of the potential energy of the undamaged and cracked material.

At the mesoscopic scale, the reinforcement architecture of woven composites is approximatively periodic, even if some variations are induced during the manufacturing process. Olave et al. [37] have shown that these variations do not significantly influence the mechanical properties of the composite. Moreover, periodic damage patterns have been observed along the edge of a 
woven composite specimen [19]. Therefore, perfect periodicity is generally assumed to model woven composites, using an elementary pattern representative of the whole material (referred to as Representative Unit Cell or RUC) in order to reduce computational costs. In this work, the geometry of the reinforcement architecture in the RUC is obtained by compaction modeling $[19,38,39]$, which yields geometries close to those of the real composite specimens [39]. A conformal mesh of the geometry is generated using the meshing procedure developed by Grail et al. [40]. Then, discrete cracks and debond zones are inserted in the FE mesh using the mesh intersection algorithm, Z-cracks [41]. The main advantage of discrete damage modeling is the possibility of directly describing localized cracks and debond zones observed experimentally (Figure 4).

The potential energy of the undamaged and cracked RUCs are determined through FE calculations. The meshes of the cracked and undamaged RUCs have exactly the same topology and only differ because the nodes describing the crack surface are doubled in the cracked mesh [24]. Periodic boundary conditions [12] are applied to the fabric plane directions of the RUC, whereas the top and bottom surfaces are left free according to the real boundary conditions of the specimen during tensile tests. The matrix behavior is assumed to be linear elastic, and the mechanical properties given by the manufacturer are: Young's modulus $E_{m}=$ 3.2 GPa, and Poisson's ratio $\nu_{m}=0.35$. Micro-meso homogenization [10] is followed to obtain the yarn behavior, using $E_{f}=73.6 \mathrm{GPa}[42]$ and $\nu_{f}=0.3$ for the fibers. The fiber volume fraction in the yarns is chosen so that the overall fiber volume fraction in the RUC is equal to the fiber volume fraction in the composite specimen. A transversely isotropic elastic behavior is obtained for the yarns, with $E_{l}=41.0 \mathrm{GPa}, E_{t}=9.8 \mathrm{GPa}, \nu_{t t}=0.32$ and $G_{l t}=7.2 \mathrm{GPa}$ (the indices $l$ and $t$ refer, respectively, to the fiber and transverse directions). The local orientation of the yarn is computed at each integration point through orthogonal projection of its position on the neutral axis of the yarn. The tangent to the neutral axis at the projected point defines the axis of transverse isotropy of the yarn material (i.e., the fiber direction) at the integration point. In the following, the influence of the fracture mode is neglected. A constant and modeindependent critical energy release rate $G^{c}$ is assumed for the yarns. As the inserted yarn cracks 
are orthogonal to the loading direction, yarn cracking will occur mostly in mode I. The value, $G^{c}=118 \mathrm{~J} / \mathrm{m}^{2}$, has been taken from a published study on a similar material [45].

\section{Damage growth modeling}

\subsection{Hypotheses on crack configuration}

Since the crack shape is not known a priori, hypotheses must be formulated in order to limit the number of possible crack configurations at damage initiation and therefore the number of calculations required to compute the incremental energy release rate. The first hypothesis is that the crack plane is parallel to the fiber direction since the fiber strength is much higher than that of the matrix. The cracks are also assumed to traverse the whole yarn width with straight crack fronts, and debonding is assumed to be symmetric on each side of the crack tip with straight fronts. The crack locations are determined with a stress-based criterion [24], which gives a good estimate of the crack locations [19, 23, 24], and the cracks propagate symmetrically with respect to their center. Under these hypotheses, damage is described by 2 parameters, namely, the crack length and the debond length. The number of cracks in the RUC is limited to 14 (Figure 6), which corresponds to the crack density measured experimentally just before failure. For each crack, the initiation length, strain and the corresponding debond initiation length are determined using the method presented in Ref. [24]. For the sake of simplicity, the same $G^{c}$ level as for yarn cracking is chosen for debonding. While the assumption of pure mode I fracture is a good approximation for the yarns, this is less obvious for the yarn interface debonding. For a more accurate model, mode mixity has to be taken into account together with the critical energy release rates of the yarn-yarn interface. This is possible [43, 44] with FFM to model mixed mode fracture of adhesive joints. A summary of the crack initiation results and the corresponding debond lengths obtained under these hypotheses are reported in Table 1.

\subsection{Propagation with no debonding}

An example of crack propagation with the proposed algorithm is discussed in this section. The crack under investigation (no. 14 in Table 1$)$ is located at $(x, y, z)=(8.82 \mathrm{~mm}, 4.0 \mathrm{~mm}$, 
$1.24 \mathrm{~mm})$. The crack initiation length $(1.92 \mathrm{~mm})$ and strain $\left(7.56 \times 10^{-3}\right)$ have been determined using the method presented in Ref. [24]. The crack surface increment is $\Delta S=0.01 \mathrm{~mm}^{2}$ (about $1 / 300^{\text {th }}$ of the area of a crack crossing the whole RUC, corresponding to a crack length increment of about $0.03 \mathrm{~mm}$ ) and the strain increment is $\Delta \epsilon=10^{-6}$. Figure 5 shows the change in crack length as a function of strain obtained with the propagation algorithm if the energy surplus is entirely used for further crack propagation (an example highlighting the differences obtained by taking into account or not the dissipation of the energy surplus is presented in the next section). Crack propagation is stable after crack initiation up to $d_{c}=4.6 \mathrm{~mm}$ and for $d_{c}>5.7 \mathrm{~mm}$, whereas it is unstable for $4.6 \mathrm{~mm}<d_{c}<5.7 \mathrm{~mm}$.

\subsection{Crack and debonding propagation}

The initiation configuration of a crack without debonding maximizes the incremental energy release rate [24]. At this maximum, $G^{i n c}=G=G^{c}$ and $\frac{d G}{d S}<0$, so that the propagation of a crack without debonding would be stable. However, it has been shown [24] that debonding can be initiated on a finite length at the crack initiation strain. After debonding initiation, the crack configuration may not correspond to a maximum of the energy release rate (Figure 7(a)). Therefore, crack propagation can either be stable (see Equation (6)) or unstable (Equation (7)). The propagation of cracks and debond zones is modeled using the algorithm presented in Section 3. For each iteration, the energy release rate for pure crack or pure debonding propagation is determined. For all studied cracks, the energy release rate for crack propagation is higher than for debonding propagation, regardless of crack length. Therefore, crack propagation is modeled with a constant debond length equal to the initiation length.

Figure 7(b) shows the change in crack length (modeled with and without debonding) as a function of strain for crack no. 14 (Figure 6). After initiation, propagation is unstable (respectively stable) if debonding is (respectively is not) taken into account. If debonding is accounted for, crack propagation is unstable from $1.92 \mathrm{~mm}$ (initiation length) to $6.7 \mathrm{~mm}$, if the energy surplus is used for further crack propagation (respectively, $5.1 \mathrm{~mm}$, if the energy surplus is dissipated). In both cases, crack propagation is accelerated by debonding. 
The change in the surface of the 14 cracks (with and without debonding) as a function of strain is computed using the algorithm presented in Section 3. The propagation of a crack is first modeled without taking into account the influence of other cracks in the RUC. The crack density is determined as the ratio between the total crack surface and the RUC volume. Figure 8 shows the change in crack density as a function of strain for cracks with and without debonding, and with and without using the energy surplus for further crack propagation. In the case of cracks with no debonding, using the energy surplus for crack propagation, or not, has very little influence on damage growth since crack propagation is mostly stable. If debonding is taken into account (blue lines in Figure 8), crack propagation is locally accelerated when the energy surplus is used for further crack propagation (dashed blue line in Figure 8). However, similar damage growth is obtained in both cases. Compared to the levels obtained without debonding (gray and black lines in Figure 8), damage growth is accelerated if debonding is accounted for, which is mainly due to debonding initiations that make crack propagation temporarily unstable. A saturation of the crack density is observed for $\epsilon>0.01$, which results from the limited number of modeled cracks. This phenomenon is not observed experimentally since the highest crack density measured before failure is $0.22 \mathrm{~mm}^{-1}$.

\subsection{Interaction between cracks}

Except for the first crack, cracks initiate and propagate in the presence of other cracks in the damaged composite. It is thus necessary to evaluate the influence of a crack on the initiation and propagation of other cracks.

First, the influence of a crack on the initiation of a second crack is studied when the second crack is located in a yarn that is not in contact with the yarn that contains the first crack (Figure 9(a)). The second crack initiation is modeled with or without the presence of the first crack, which is $3.4 \mathrm{~mm}$ or $10 \mathrm{~mm}$ long. The second crack initiation lengths $(1.28 \mathrm{~mm}$ in all three cases) and strains $\left(6.49 \times 10^{-3}, 6.50 \times 10^{-3}\right.$ and $\left.6.54 \times 10^{-3}\right)$ are very close, which means that the first crack has a negligible influence on the second crack initiation if both cracks are located in two different yarns that are not in contact. 
The influence of a crack on the initiation of a second crack is now studied when the two cracks are located in the same yarn (Figure 9(b)). The initiation strain of the second crack is calculated as a function of the distance between the cracks along the warp direction $(\Delta x)$ for the second crack of length $0.6 \mathrm{~mm}$ (Figure 10(a)) or $5.5 \mathrm{~mm}$ (Figure 10(b)) with, or without, the presence of the first crack, which is $10 \mathrm{~mm}$ long. If both cracks are separated by more than about $1 \mathrm{~mm}$, the influence of the first crack on the initiation of the second crack is negligible. Therefore, they can be treated separately. However, if both cracks are close to each other, it is necessary to take into account their coupling since a higher second crack initiation strain is obtained in the presence of the first crack.

Among the 14 studied cracks, 6 couplings are considered (cracks no. 4 and 7, no. 3 and 6, no. 5 and 8 , no. 9 and 14 , no. 11 and 12 , no. 13 and 14). For each pair of cracks, the first crack initiation length, strain and debond length are calculated. Then, the second crack initiation length $d_{2}$ and strain $\epsilon$ are determined, taking into account the possibility for the first crack (whose initiation length is $d_{1}$ ) to propagate by an increment $\delta d_{1}$. This is achieved by performing a new energy balance

$$
W\left(d_{1}, 0, \epsilon\right)-W\left(d_{1}+\delta d_{1}, d_{2}, \epsilon\right)=G^{c}\left(S\left(d_{1}+\delta d_{1}\right)-S\left(d_{1}\right)+S\left(d_{2}\right)\right)
$$

which can be solved using the algorithm presented in Section 3 .

The results for each pair of cracks are summarized in Table 2. The next step consists in determining the debond length of the second crack (Table 2). Last, the propagation of both cracks is determined, assuming that the debond lengths are constant during crack propagation. Figure 11 shows a comparison of damage growth obtained taking into account, or not, the coupling between close cracks, with and without debonding. For strain levels lower than $8 \times$ $10^{-3}$, the influence of coupling is negligible since only one crack pair is active. For higher strain levels, the coupling between cracks tends to slow down crack propagation. 


\section{Comparison between numerical and experimental results}

In this section, the damage growth obtained taking into account the coupling between close cracks and debonding around the crack front is compared to the experimental observations. Figures 12 and 13 show the change in crack and debond densities as functions of the macroscopic strain. The critical energy release rate of the yarns was first taken from the work of Benzeggagh and Kenane [45] who studied a unidirectional glass fiber/epoxy matrix composite. Their value of $G^{c}=118 \mathrm{~J} / \mathrm{m}^{2}$ leads to a good estimate of the initiation strain determined by acoustic emission [24]. However, the crack density growth is overestimated compared to the experimental data (Figure 12). A reason might be that the material studied in Ref. [45] was made with a different epoxy matrix than the composite studied herein. Further, under the assumption of linear elastic fracture mechanics, the strain at which a given crack density is reached is proportional to the square root of $G^{c}$. A better estimate of the crack density is obtained for $G^{c}=200 \mathrm{~J} / \mathrm{m}^{2}$. However, the initiation strain of the first crack predicted with this $G^{c}$ level is higher than the first AE signal associated with damage [24]. A similar result is obtained for the debond density growth, which is overestimated for $G^{c}=118 \mathrm{~J} / \mathrm{m}^{2}$ and in better agreement with the experimental data for $G^{c}=200 \mathrm{~J} / \mathrm{m}^{2}$. These results indicate that the real critical energy release rate of the yarns is probably closer to $200 \mathrm{~J} / \mathrm{m}^{2}$ levels than $118 \mathrm{~J} / \mathrm{m}^{2}$. The initiation strain of the first crack is more dependent on local variations of the material such as defects or residual stresses than the change in the overall crack density.

Despite the simplification of not taking into account the mode mixity in the model and using the same $G^{c}$ level for yarn cracking and debonding, the change of both crack and debond densities is well reproduced if an appropriate value for $G^{c}$ is chosen. This value may be of limited physical meaning since it is unified $G^{c}$ for yarn cracking and debonding that is mode independent. However, the level, $G^{c}=200 \mathrm{~J} / \mathrm{m}^{2}$, seems to be a reasonable value for the yarns, since the critical energy release rate of the matrix given by the manufacturer is $280 \pm 25 \mathrm{~J} / \mathrm{m}^{2}$.

The relationship between the debond density and the crack density shown in Figure 14 is independent of $G^{c}$ under the assumption that the critical energy release rate is the same 
for cracks and debonding. This assumption is supported by the fact that both cracking and debonding result from inter-fiber matrix cracking at the microscopic scale. The change in debond density with respect to the crack density agrees well with the experimental data.

Figure 15 shows the damaged RUC corresponding to the 4 measured crack densities. A comparison of the experimental and numerical damage states at these 4 load levels is shown in Figures 16 to 19. For high crack density levels, most experimentally observed cracks appear at similar locations over the whole specimen edge, showing a certain periodicity of damage within the material. In addition, some variability is observed within the zones with repeating damage patterns, both in terms of crack location and number. Moreover, several crack locations are observed only once. For lower crack density levels, less periodic patterns are observed. This may be due to cracks that have been initiated inside the specimen but have not yet propagated to the observed edge. Local phenomena such as, e.g., variations in the reinforcement architecture [37], defects or porosities, residual stresses due to the manufacturing process, also have an influence on crack initiation strain, location and propagation.

Last, the influence of damage on the macroscopic mechanical behavior of the composite is obtained from meso-macro homogenization. The calculated Young's modulus in the warp direction and the in-plane Poisson's ratio are in good agreement with the experimental data (Table 3).

\section{Conclusions}

The proposed approach, which is based on discrete damage modeling in a representative unit cell of a woven composite at the mesoscopic scale, allows damage growth in the composite to be determined. Crack and debonding propagations are estimated by computing the incremental energy release rate for small surface increments. The propagation of a crack without debonding is stable after crack initiation. However, debonding initiation can make the propagation unstable and tends to accelerate crack propagation. Moreover, after initiation, the debond length does not change before the crack has fully propagated through the entire unit cell. The crack density change is slightly accelerated if debonding is accounted for, compared to the case 
of an absence of debonding.

The presence of a crack delays the initiation of additional cracks in its vicinity and slows down their propagation. However, if two cracks are separated by more than $1 \mathrm{~mm}$ from each other, this coupling becomes negligible and their propagations can be treated separately. The change in debond density is correlated to that of crack density. This correlation is independent of the value taken for the critical energy release rate, $G^{c}$, and agrees well with the experimental observations. Good quantitative agreement between calculated crack and debond densities and experimental observations is obtained for a critical energy release rate $G^{c}=200 \mathrm{~J} / \mathrm{m}^{2}$. However, for this $G^{c}$ level, the calculated initiation strain of the first crack is significantly higher than the first acoustic emission signal associated with damage. A possible explanation could be the strong influence on the first crack initiation of local variations within the material such as manufacturing defects or residual stresses.

For a more in-depth comparison of the predicted damage growth, computed microtomography observations would be required in order to observe the real 3D crack shapes. Future work will aim at improving the proposed approach, e.g., by modeling non symmetrical propagation of the cracks or by taking into account more complex crack shapes.

\section{References}

[1] Hochard C, Aubourg PA, Charles JP. Modelling of the mechanical behaviour of woven-fabric CFRP laminates up to failure. Compos Sci Technol 2001;61:221-30.

[2] Barbero EJ, Lonetti P, Sikkil KK. Finite element continuum damage modeling of plain weave reinforced composites. Compos Part B 2005;37(2-3):137-47.

[3] Maire JF, Chaboche JL. A new formulation of continuum damage mechanics (CDM) for composite materials. Aerospace Sci Technol 1997;1(4):247-57.

[4] Marcin L, Carrère N, Maire JF. A macroscopic visco-elastic-damage model for three dimensional woven fabric composite. In: Proceedings of ECCM13 - $13^{\text {th }}$ European Conference on Composite Materials, Stockholm, Sweden, 2008.

[5] Rakotoarisoa C, Laurin F, Hirsekorn M, Maire JF, Olivier L. Development of a fatigue model for 3D woven polymer matrix composites based on a damage model. In: Proceedings of ECCM15 - $15^{\text {th }}$ European Conference on Composite Materials, Venice, Italy, 2011, paper 101.

[6] Elias A, Laurin F, Kaminski M, Gornet L. Experimental and numerical investigations of low energy/velocity impact damage generated in 3D woven composite with polymer matrix. Compos Struct 2017;159:228-39. 
[7] Hurmane A, Irisarri FX, Laurin F, Leclercq S, Benzeggagh M. Strength analysis of woven interlock composites subjected to compressive loading: experiments and simulations. In: Proceedings of ECCM16 - $16^{\text {th }}$ European Conference on Composite Materials, Seville, Spain, 2014.

[8] Gao XL, Li K, Mall S. A mechanics-of-materials model for predicting Young's modulus of damaged woven fabric composites involving three damage modes. Int J Solids Struct 2003;40:981-99.

[9] Daggumati S, Van Paepegem W, Degrieck J, Xu J, Lomov SV, Verpoest I. Local damage in a 5-harness satin weave composite under static tension: Part II - Meso-FE modelling. Compos Sci Technol 2010;70:1934-41.

[10] Melro P, Camanho P, Andrade Pires FM, Pinho ST. Numerical simulation of the non-linear deformation of 5-harness satin weaves. Comput Mater Sci 2012;61:116-26.

[11] Zako M, Uetsuji Y, Kurashiki T. Finite element analysis of damaged woven fabric composite materials. Compos Sci Technol 2003;63:507-16.

[12] Lomov SV, Ivanov DS, Verpoest I, Zako M, Kurashiki T, Nakai H, Hirosawa S. Meso-FE modelling of textile composites: Road map, data flow and algorithms. Compos Sci Technol 2007;67(9):1870-91.

[13] Gorbatikh L, Ivanov D, Lomov SV, Verpoest I. On modelling of damage evolution in textile composites on meso-level via property degradation approach. Compos Part A 2007;38:243342.

[14] Allix O, Feissel P, Thevenet P. A delay damage mesomodel of laminates under dynamic loading: basic aspects and identification issues. Comput Struct 2003;81:1177-91.

[15] Maimí P, Camanho PP, Mayugo JA, Davila CG. A continuum damage model for composite laminates: Part II - Computational implementation and validation. Mech Mater 2007;39:909-19.

[16] John S, Herszberg I, Coman F. Longitudinal and transverse damage taxonomy in woven composite components. Compos Part B 2001;32(8):659-68.

[17] Osada T, Nakai A, Hamada H. Initial fracture behavior of satin woven fabric composites. Compos Struct 2003;61:333-9.

[18] Daggumati S, De Baere I, Van Paepegem W, Degrieck J, Xu J, Lomov SV, Verpoest I. Local damage in a 5-harness satin weave composite under static tension: Part I - Experimental analysis. Compos Sci Technol 2010;70(13):1926-33.

[19] Doitrand A, Fagiano C, Chiaruttini V, Leroy FH, Mavel A, Hirsekorn M. Experimental characterization and numerical modeling of damage at the mesoscopic scale of woven polymer matrix composites under quasi-static tensile loading. Compos Sci Technol 2015;119:111.

[20] Le Page BH, Guild FJ, Ogin SL, Smith PA. Finite element simulation of woven fabric composites. Compos Part A 2004;35:861-72.

[21] Couegnat G. Approche multiéchelle du comportement mécanique de matériaux composites à renfort tissé. Doctorate thesis, Université de Bordeaux 1, 2008. https://tel.archivesouvertes.fr/tel-00403885/.

[22] Obert E, Daghia F, Ladevèze P, Ballere L. Micro and meso modeling of woven composites: Transverse cracking kinetics and homogenization. Compos Struct 2014;117:212-21.

[23] Faes JC, Rezaei A, Van Paepegem W, Degrieck J. Accuracy of 2D FE models for prediction of crack initiation in nested textile composites with inhomogeneous intra-yarn fiber volume 
fractions. Compos Struct 2016;140:11-20.

[24] Doitrand A, Fagiano C, Carrère N, Chiaruttini V, Hirsekorn M. Damage onset modeling in woven composites based on a coupled stress and energy criterion. Eng Fract Mech, doi:10.1016/j.engfracmech.2016.11.021.

[25] Gao F, Boniface L, Ogin SL, Smith PA, Greaves RP. Damage accumulation in wovenfabric CFRP laminates under tensile loading: Part 1. Observations of damage accumulation. Compos Sci Technol 1999;59:123-36.

[26] Rupil J, Roux S, Hild F, Vincent L. Fatigue microcrack detection with digital image correlation. J Strain Analysis 2011;46:492-509.

[27] Hild F, Bouterf A, Roux S. Damage measurements via DIC. Int J Fract 2015;191:77-105.

[28] Tomičević Z, Hild F, Roux S. Mechanics-aided digital image correlation. J Strain Analysis 2013;48(5):330-43.

[29] Weissgraeber P, Hell S, Becker W. Crack nucleation in negative geometries. Eng Fract Mech 2016;in press, doi:10.1016/j.engfracmech.2016.02.045.

[30] Griffith AA. The phenomenon of rupture and flows in solids. Phil Trans Roy Soc (London) 1920;221(582-593):163-98.

[31] Hashin Z. Finite thermoelastic fracture criterion with application to laminate cracking analysis, J Mech Phys Solids 1996;44(7):1129-45.

[32] Leguillon D. Strength or Toughness? A criterion for crack onset at a notch. Eur J Mech A/Sol 2002;21:61-72.

[33] Destuynder P, Djaoua M, Lescure S. Quelques remarques sur la mécanique de la rupture élastique. J Méc Théor Appl 1983;2(1):113-35.

[34] Ousset Y. Numerical simulation of delamination growth in layered composite plates. Eur J Mech A/Solids 1999;18:291-312.

[35] Chiaruttini V, Guilie J, Feyel F, Bonnet M, Le Tallec P. Approches par maillage conforme pour la mécanique non linéaire de la rupture : méthode G- $\theta$ et modèle de zone cohésive. $10^{\text {eme }}$ Colloque National en Calcul de Structures (CSMA) May 2011, Giens, France.

[36] Leguillon D, Lacroix C, Martin E. Interface debonding ahead of a primary crack, J Mech Phys Solids 2000;48(10):2137-61.

[37] Olave M, Vanaerschot A, Lomov S, Vandepitte D. Internal geometry variability of two woven composites and related variability of the stiffness. Polym Compos 2012;33(8):133550 .

[38] Doitrand A, Fagiano C, Irisarri FX, Hirsekorn M. Comparison between voxel and consistent meso-scale models of woven composites. Compos Part A 2015;73:143-54.

[39] Doitrand A, Fagiano C, Leroy FH, Mavel A, Hirsekorn M. On the influence of fabric layer shifts on the strain distributions in a multi-layer woven composite. Compos Struct 2016;145:15-25.

[40] Grail G, Hirsekorn M, Wendling A, Hivet G, Hambli R. Consistent Finite Element mesh generation for meso-scale modeling of textile composites with preformed and compacted reinforcements. Compos Part A 2013;55:143-51.

[41] Chiaruttini V, Riolo V, Feyel F. Advanced remeshing techniques for complex 3D crack propagation. $13^{\text {th }}$ International Conference on Fracture, Beijing, China, 2013;1:547-55.

[42] Rocher JE, Allaoui S, Hivet G, Gillibert J, Blond E. Experimental characterization and modeling of GF/PP commingled yarns tensile behavior. J Compos Mater 2015;49(21):260924. 
[43] Weissgraeber P, Becker W. Finite Fracture Mechanics model for mixed mode fracture in adhesive joints. Int J Solids Struct 2013;50:2383-94.

[44] Carrère N, Martin E, Leguillon D. Comparison between models based on a coupled criterion for the prediction of the failure of adhesively bonded joints. Eng Fract Mech 2015;138:185201.

[45] Benzeggagh M, Kenane M. Measurement of mixed-mode delamination fracture toughness of unidirectional glass/epoxy composites with mixed-mode bending apparatus. Compos Sci Technol 1996;56(4):439-49. 
(a)

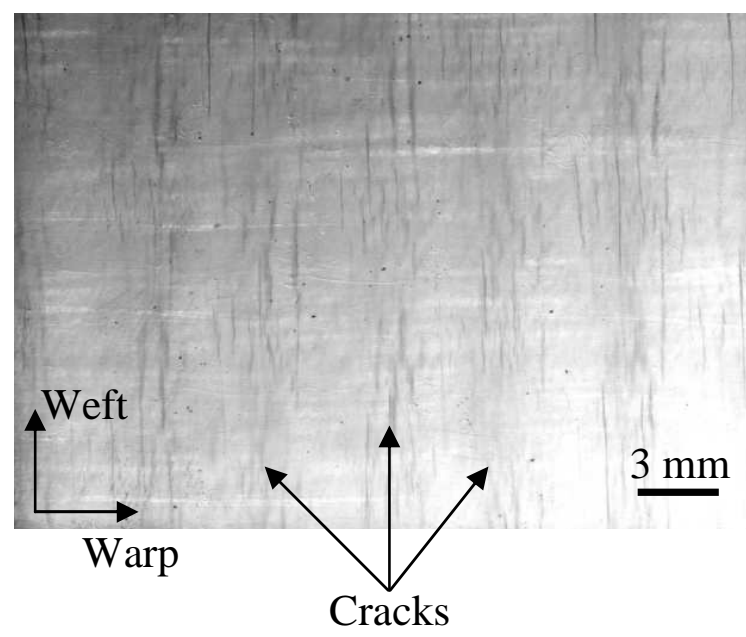

(b)

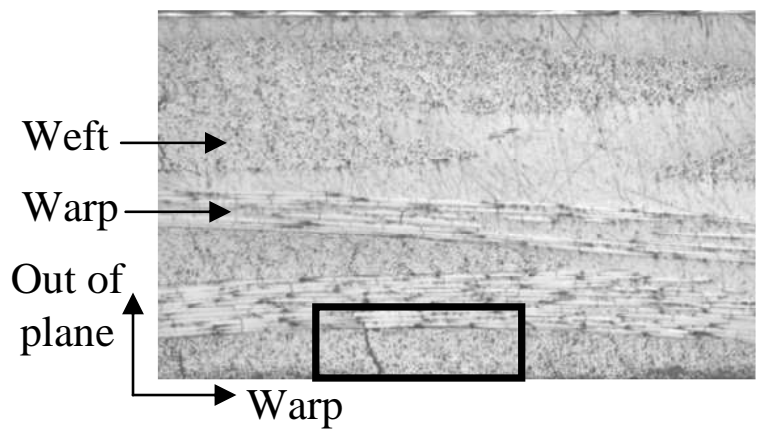

Crack

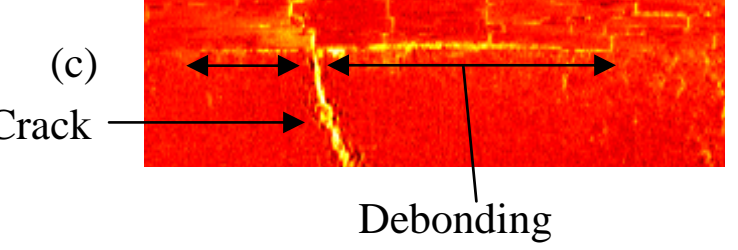

Figure 1: (a) Light transmitted front view and (b) optical micrograph of the edge of the specimen. (c) Correlation residuals over the area outlined in (b) highlighting an intra-yarn crack and debonding between yarns.

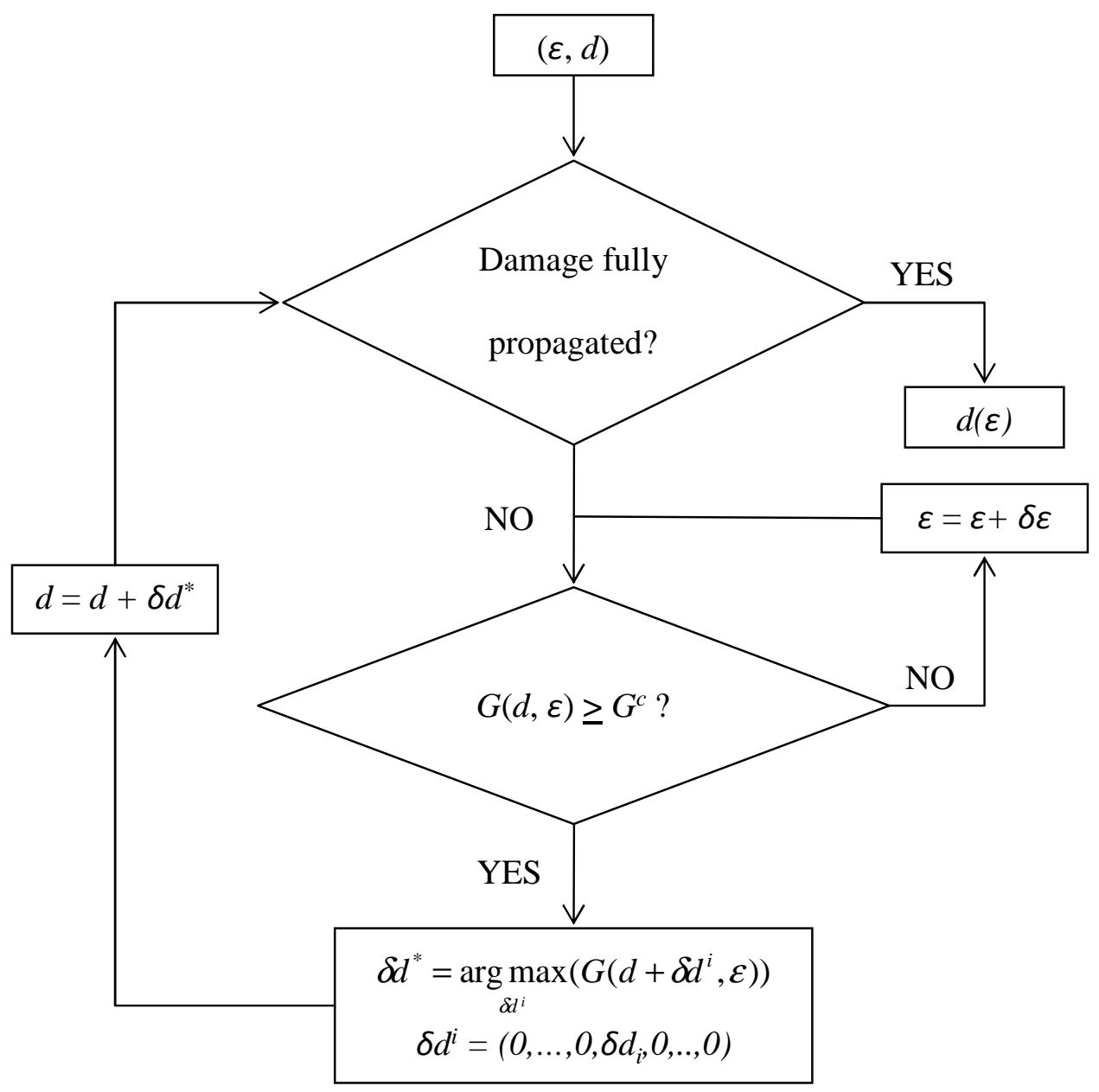

Figure 2: Algorithm used to model damage propagation in the considered representative unit cell. 
(a)

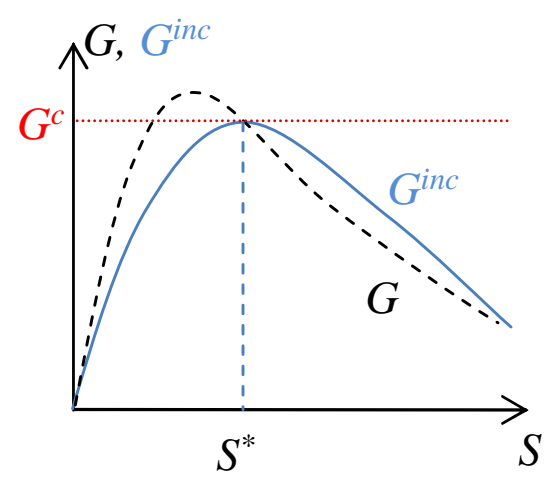

(b)

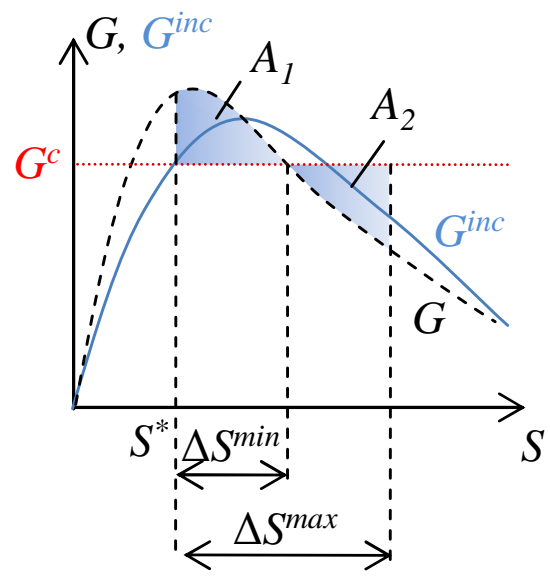

(c)

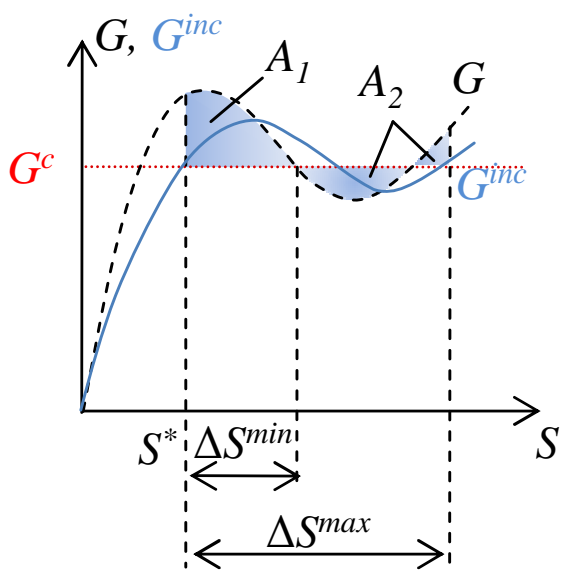

Figure 3: Incremental and differential energy release rates as functions of the crack surface in the case of (a) stable and (b-c) unstable propagations of a crack.

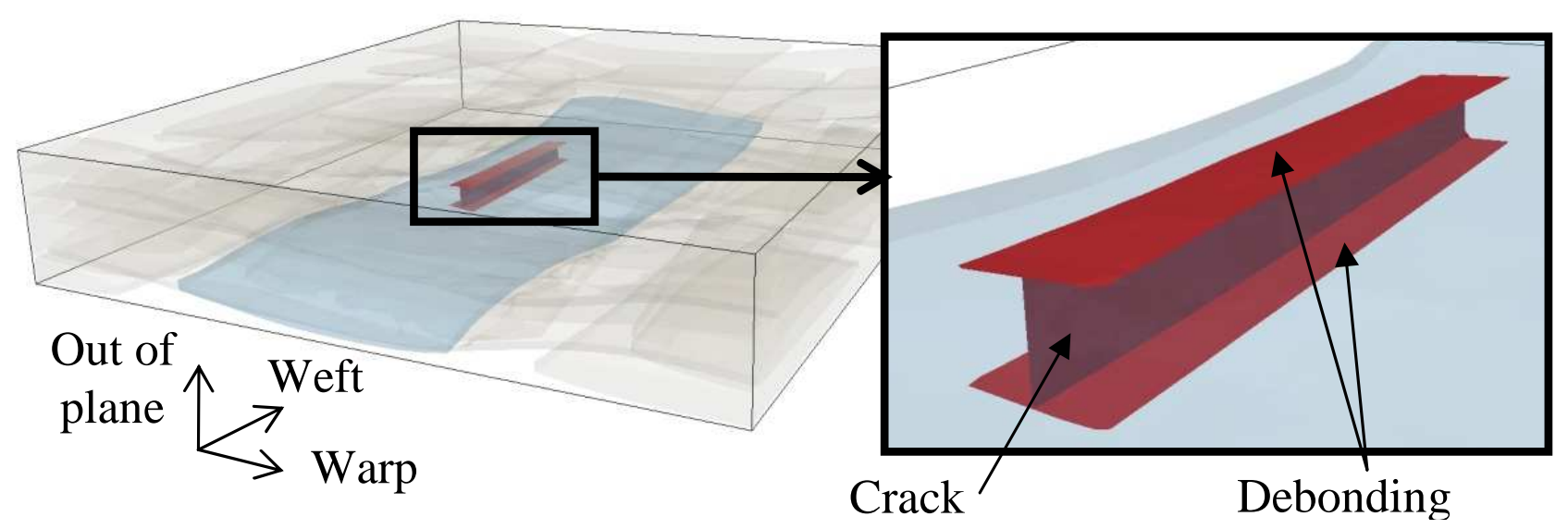

Figure 4: Discrete damage modeling in the representative unit cell of the composite. Example of an intra-yarn crack with debonding at the crack front. 


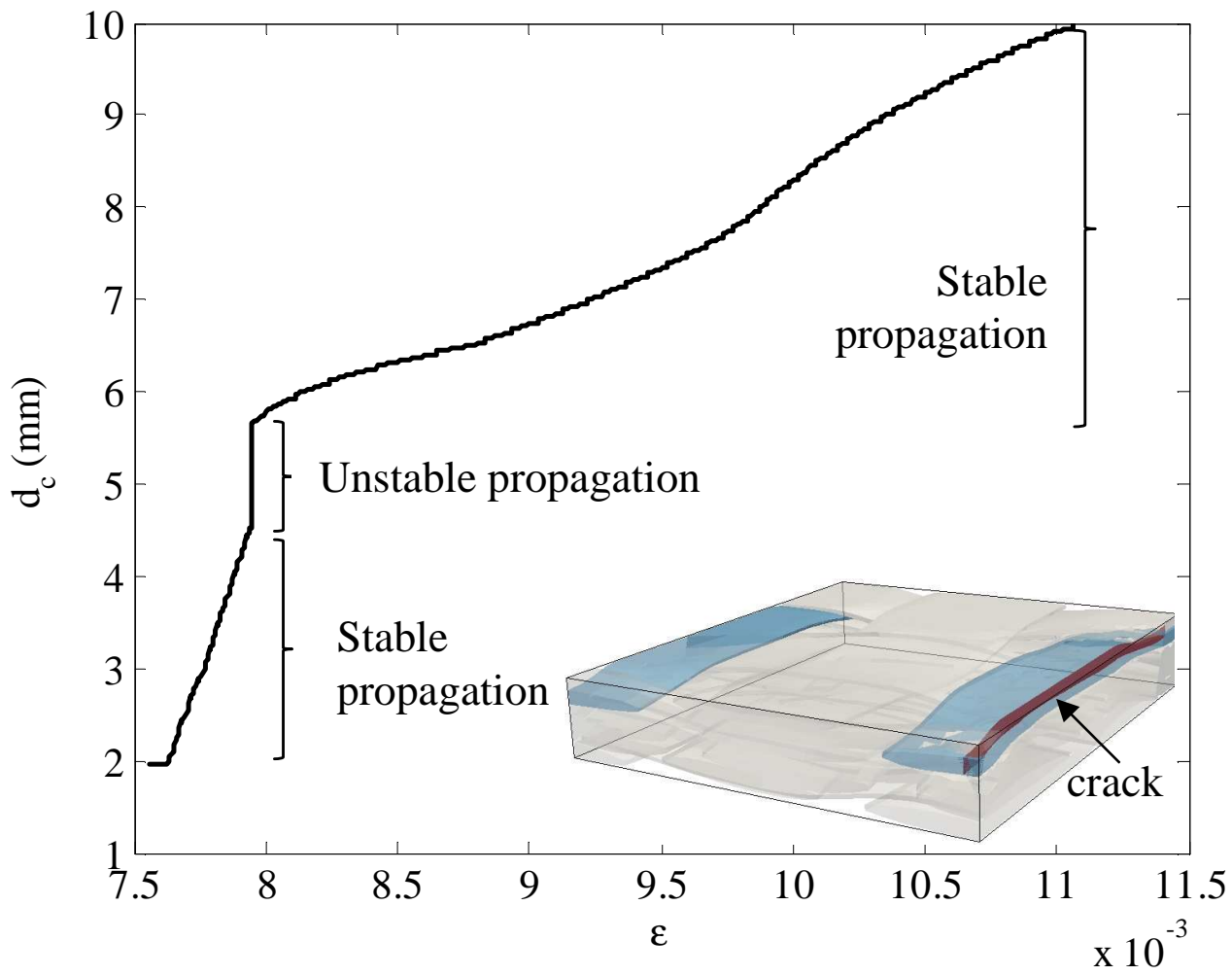

Figure 5: Crack length as a function of the macroscopic strain. Crack propagation is stable for $d_{c}<4.6 \mathrm{~mm}$ and $d_{c}>5.7 \mathrm{~mm}$, and unstable for $4.6<d_{c}<5.7 \mathrm{~mm}$.

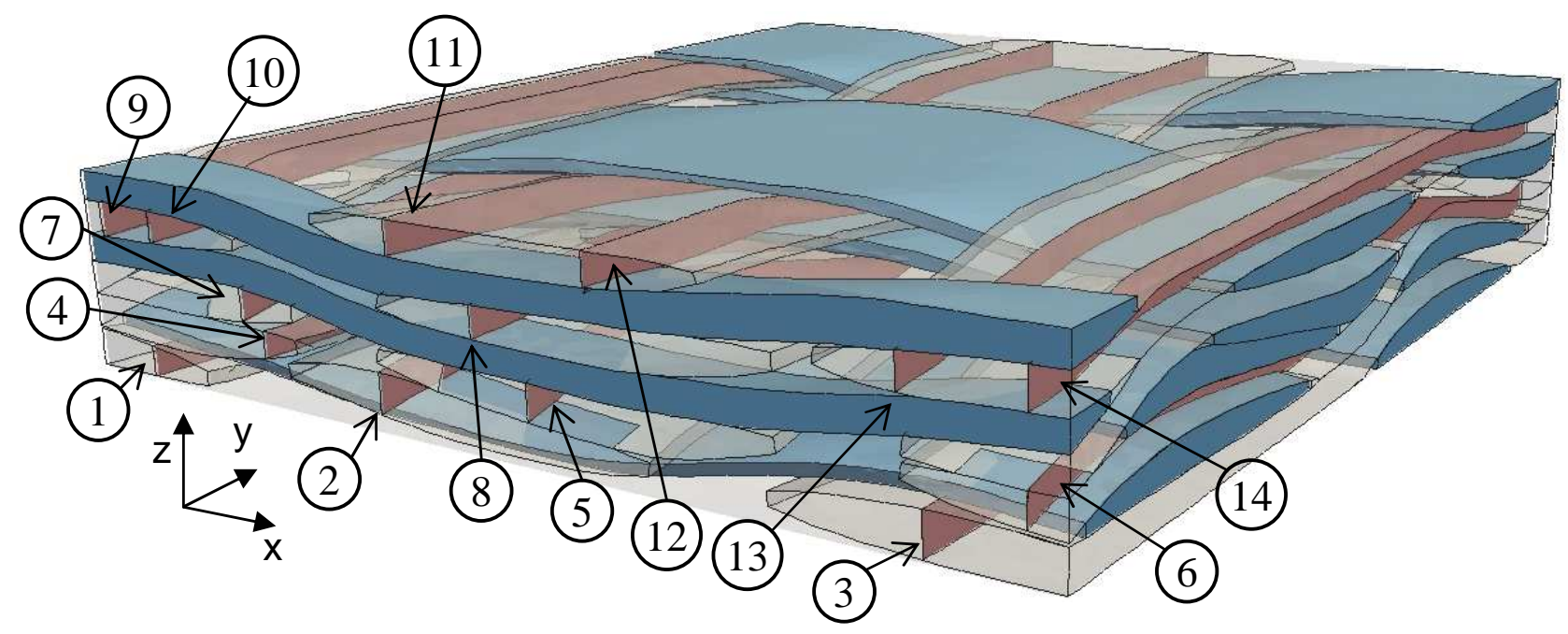

Figure 6: Damaged cell containing 14 cracks whose location is obtained using a stress-based criterion. 


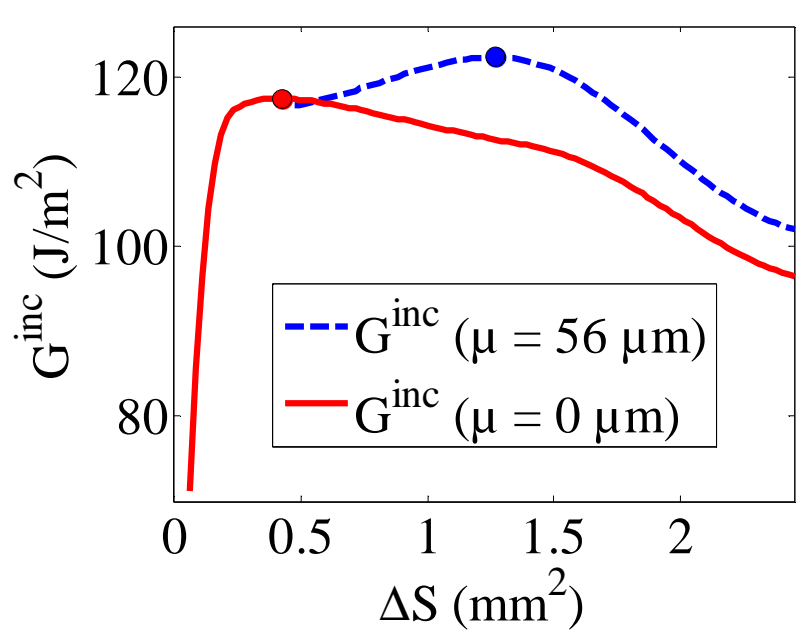

(a)

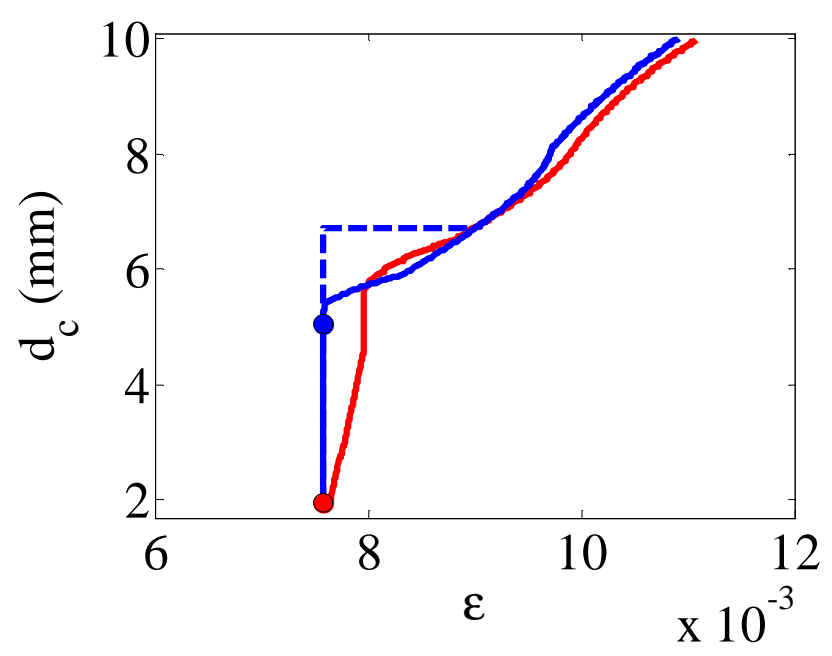

(b)

Figure 7: (a) Incremental energy release rate as a function of the crack surface (crack no. 14 in Figure 6) without (red solid line) and with (blue dashed line) debonding. (b) Crack length as a function of strain without (in red) and with (in blue) debonding, using the energy surplus released during the unstable phase for further crack propagation (dashed line) or not (solid line).

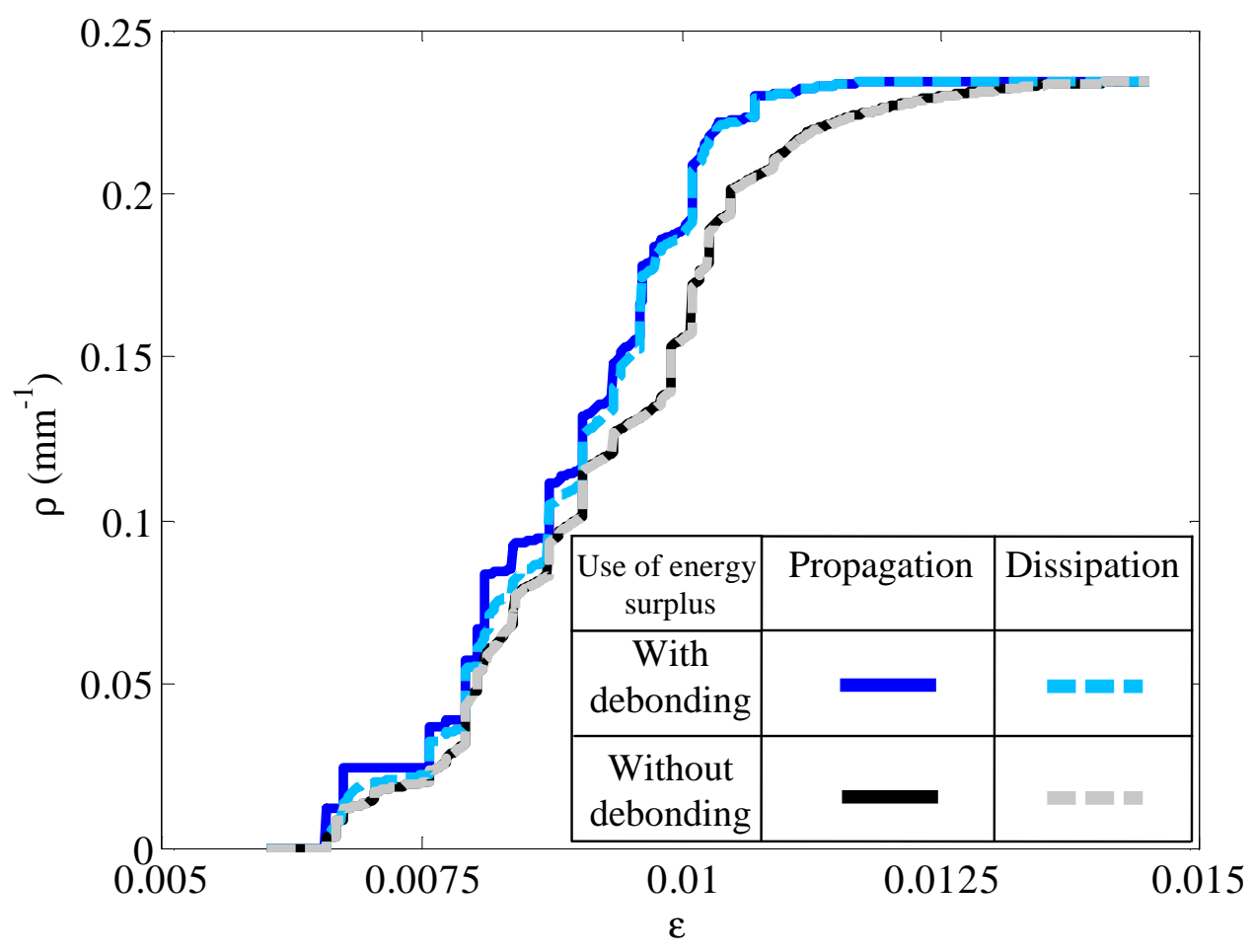

Figure 8: Crack density as a function of strain with or without debonding using the energy surplus of the unstable phase for further crack propagation, or not (dissipation). 


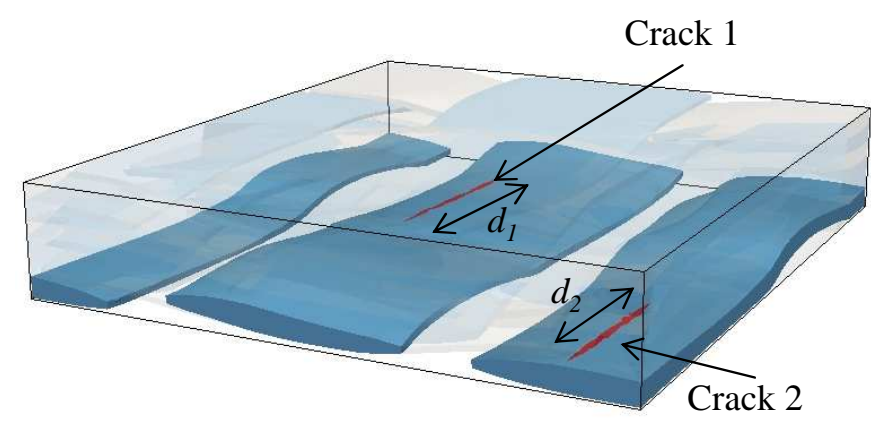

(a)

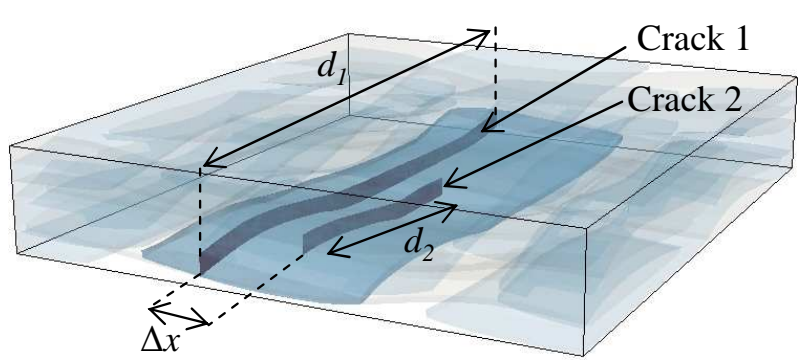

(b)

Figure 9: Damaged cell containing two cracks (a) in two different yarns and (b) in the same yarn.

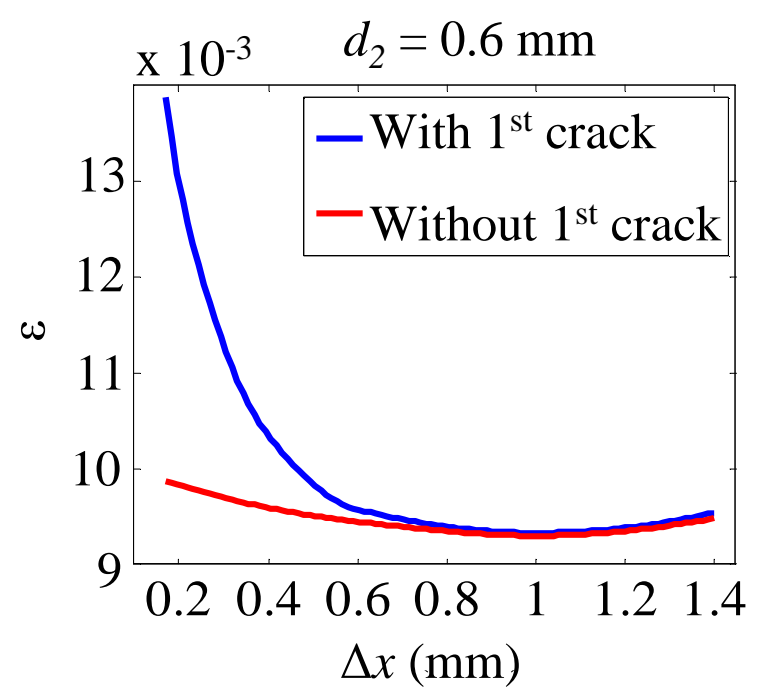

(a)

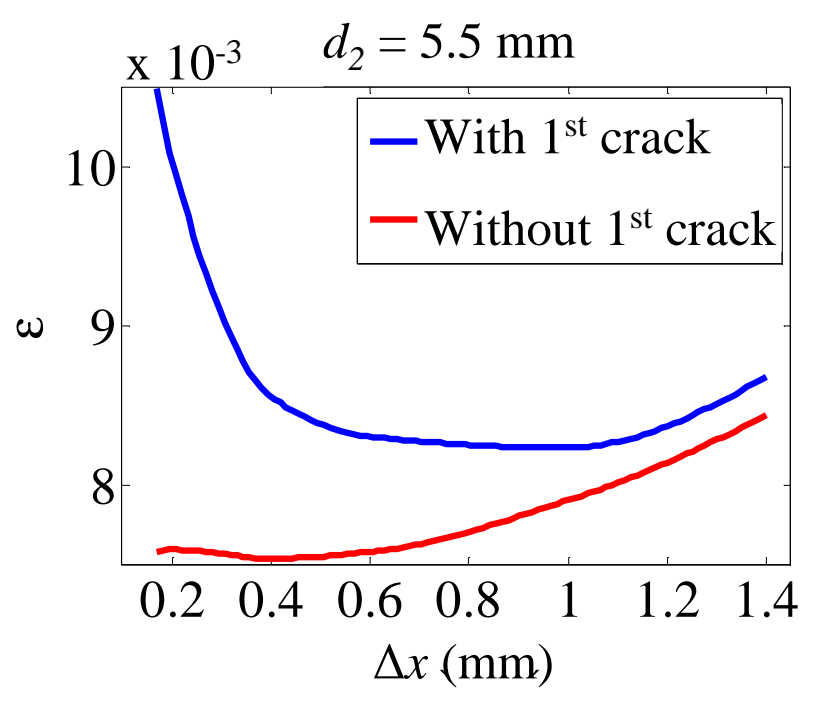

(b)

Figure 10: Initiation strain of a second crack (a) $0.6 \mathrm{~mm}$ and (b) $5.5 \mathrm{~mm}$ in length as a function of the distance $\Delta x$ along the warp direction from another crack (in blue) or without the presence of other cracks (in red). 


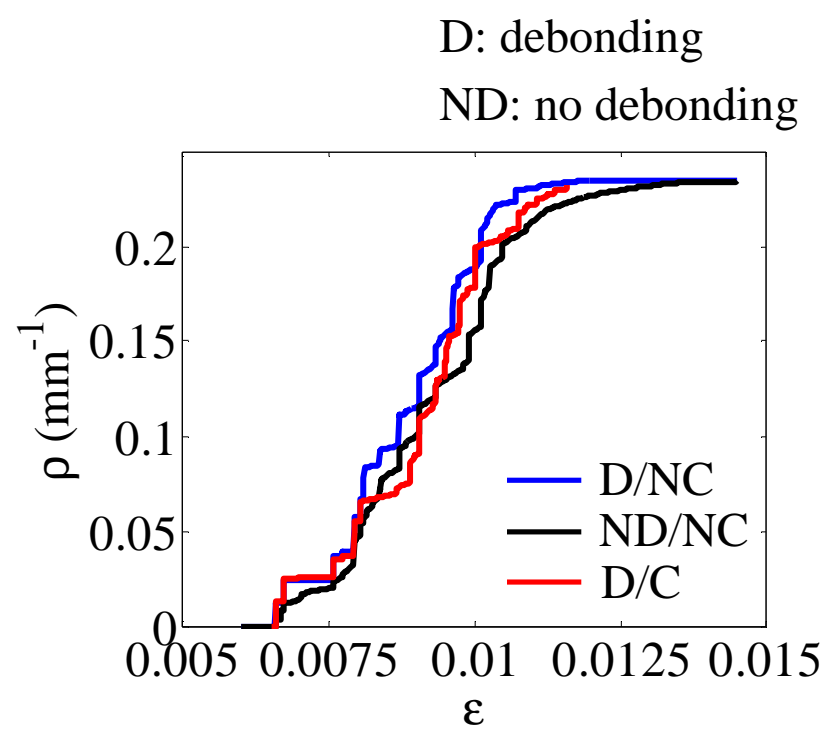

(a)
C: coupling

NC: no coupling

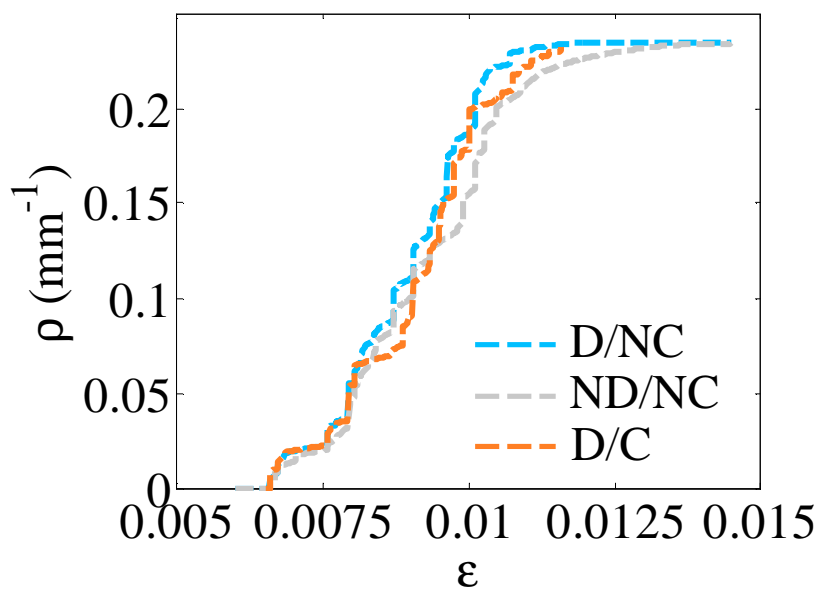

(b)

Figure 11: Comparison of damage growth obtained with or without coupling between close cracks using (a) or not (b) the energy surplus for further crack propagation.

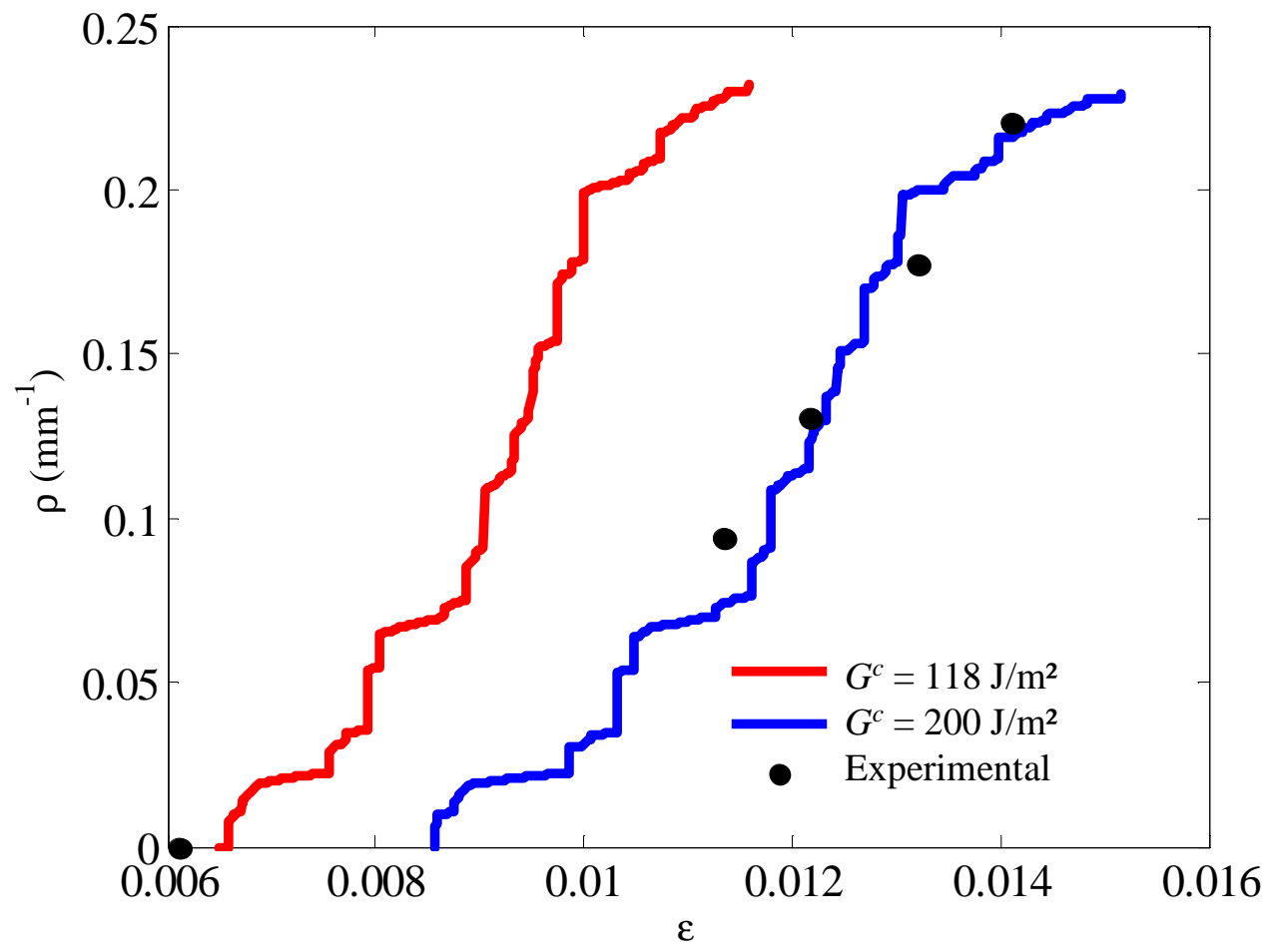

Figure 12: Crack density as a function of strain obtained when $G^{c}=118 \mathrm{~J} / \mathrm{m}^{2}$ (in red), $G^{c}=200 \mathrm{~J} / \mathrm{m}^{2}$ (in blue), and observed experimentally (in black). 


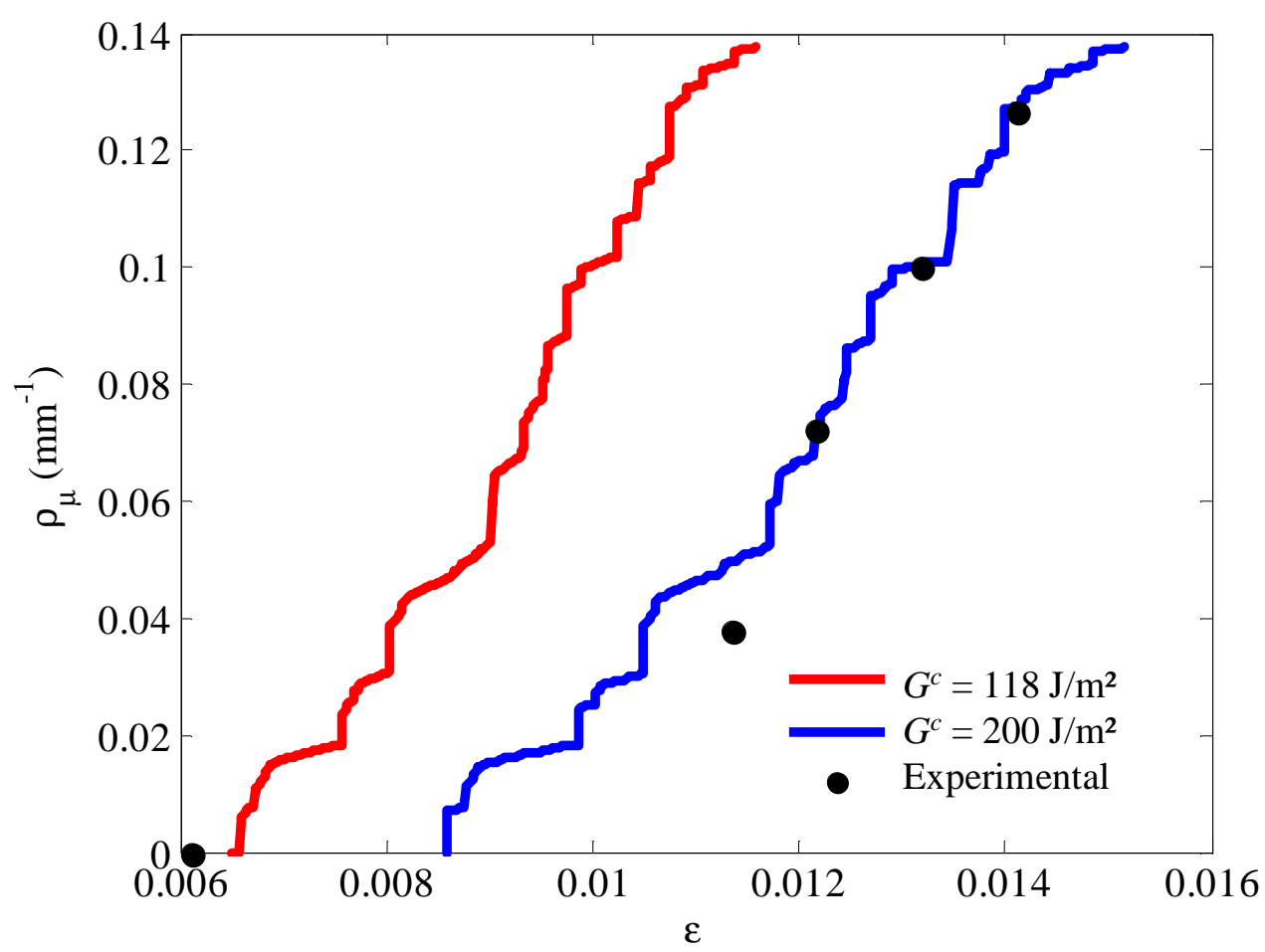

Figure 13: Debonding density as a function of strain obtained when $G^{c}=118 \mathrm{~J} / \mathrm{m}^{2}$ (in red), $G^{c}=200 \mathrm{~J} / \mathrm{m}^{2}$ (in blue), and observed experimentally (in black).

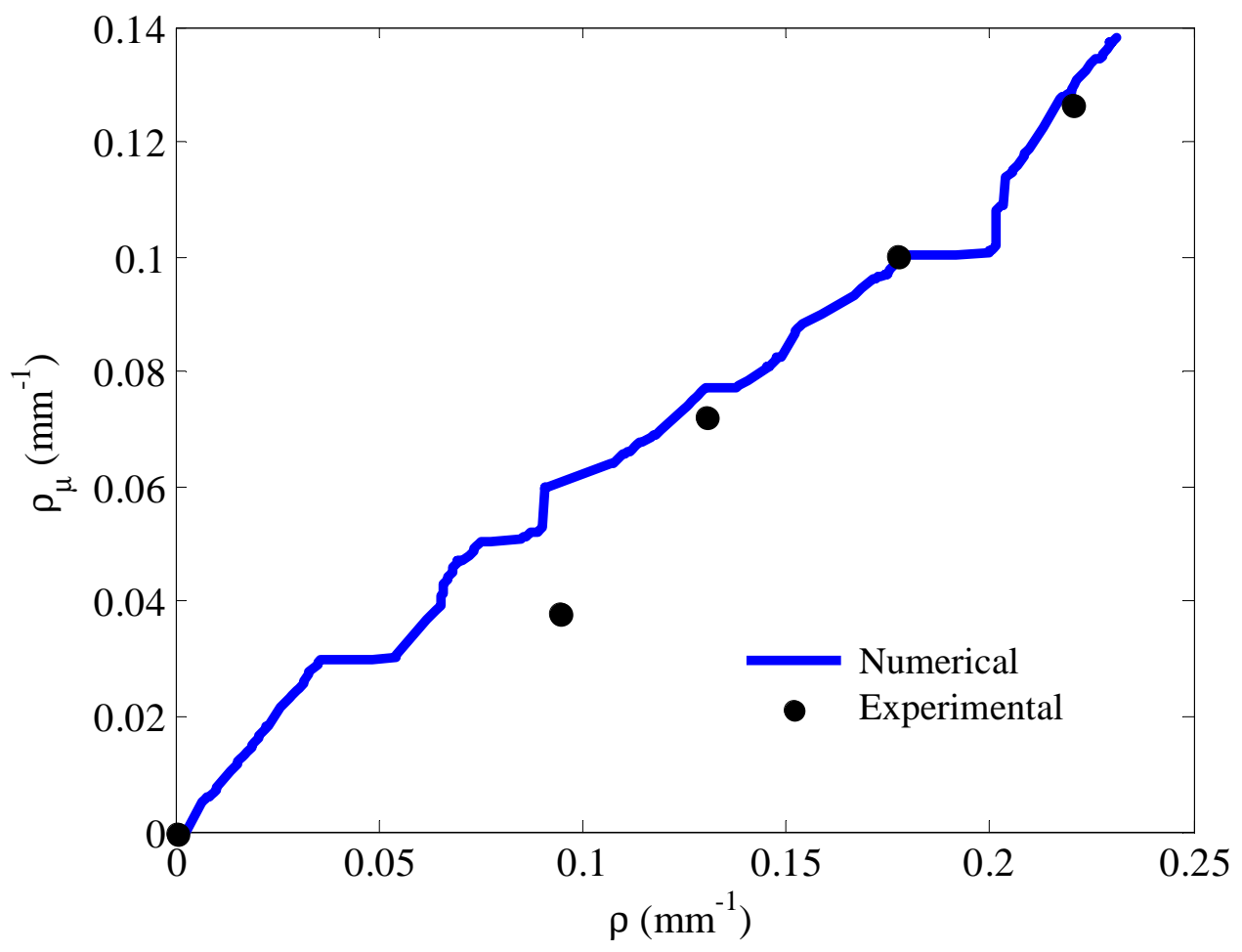

Figure 14: Relationship between debond $\left(\rho_{\mu}\right)$ and crack $(\rho)$ densities obtained numerically (in blue) and experimentally (in black). 


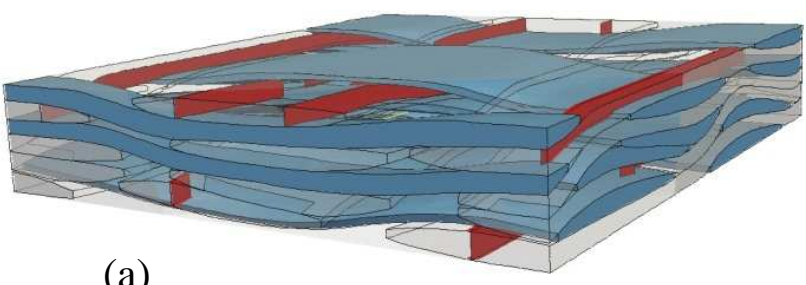

(a)

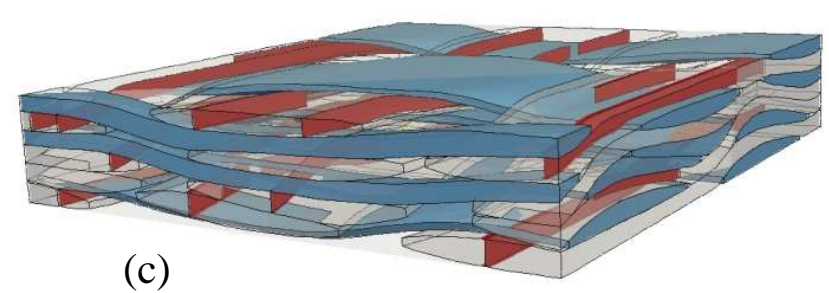

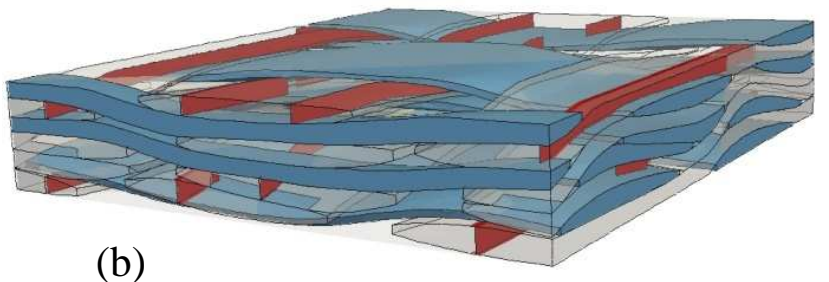

(b)

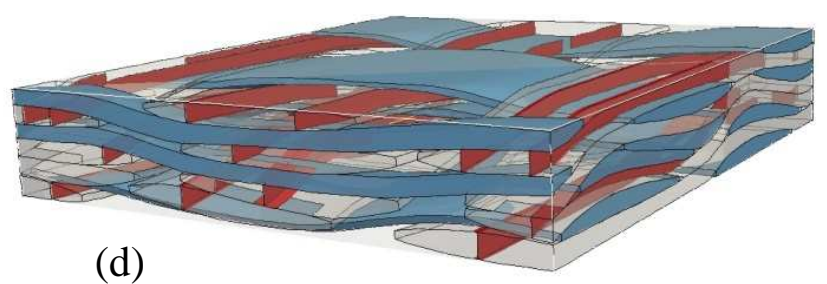

Figure 15: Damage in the cell predicted for the crack density levels measured experimentally: (a) $\rho_{c}=$ $0.09 \mathrm{~mm}^{-1}$, (b) $\rho_{c}=0.13 \mathrm{~mm}^{-1}$, (c) $\rho_{c}=0.18 \mathrm{~mm}^{-1}$, (d) $\rho_{c}=0.22 \mathrm{~mm}^{-1}$.

(a)

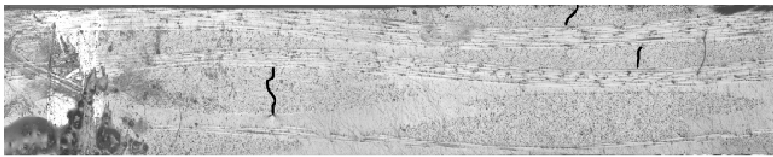

(c)

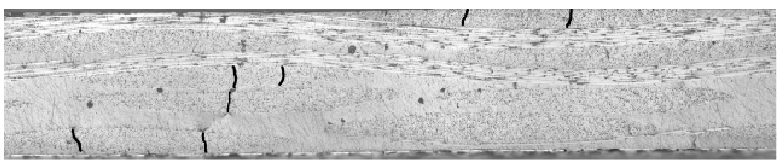

(e)

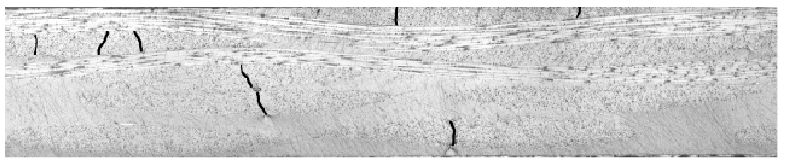

(a-e) Optical micrographs

(f) Numerical results

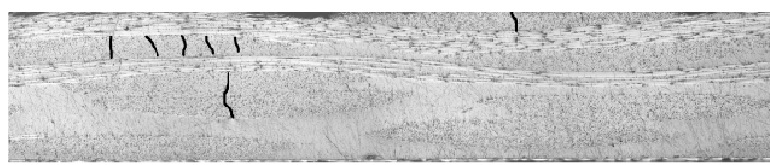

(b)
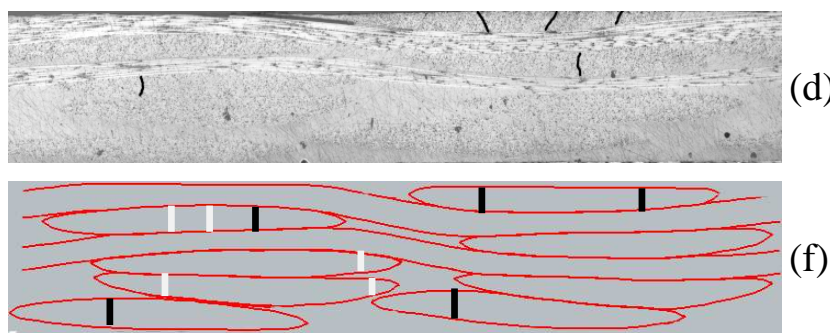

Figure 16: Comparison between crack locations (a-e) observed experimentally on the edge of the specimen and (f) obtained numerically for a crack density $\rho_{c}=0.09 \mathrm{~mm}^{-1}$. 
(a)

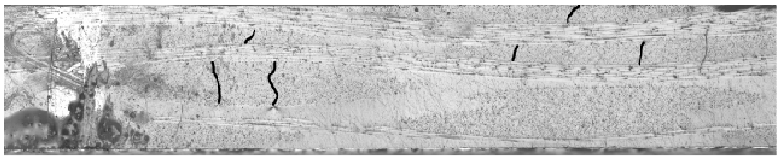

(c)

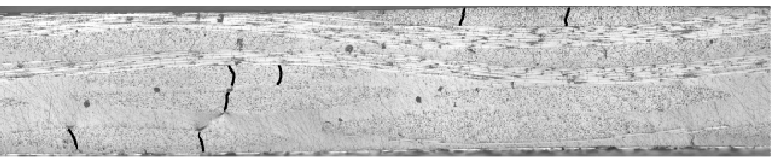

(e)

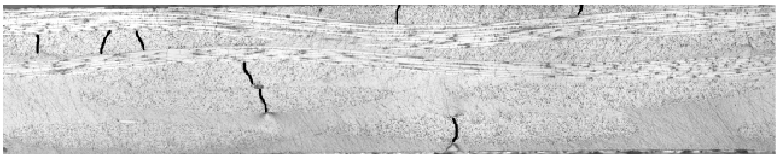

(a-e) Optical micrographs

(f) Numerical results

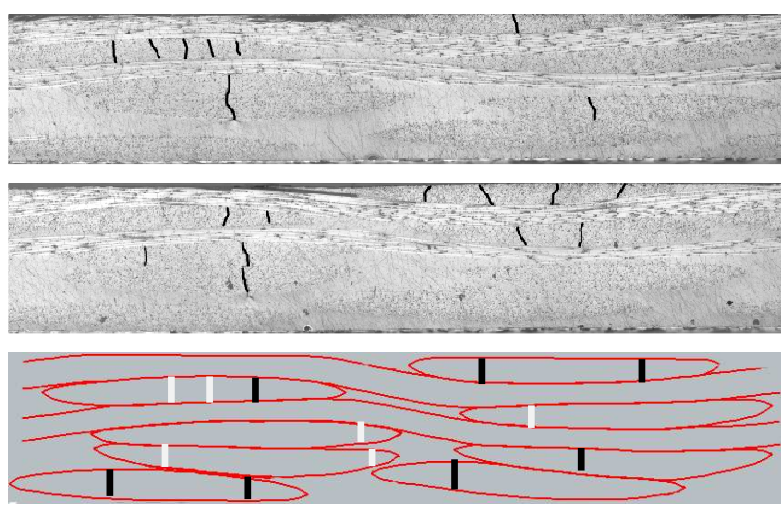

(b)

I Crack crossing the RUC edge

Crack not crossing the RUC edge

Figure 17: Comparison between crack locations (a-e) observed experimentally on the edge of the specimen and (f) obtained numerically for a crack density $\rho_{c}=0.13 \mathrm{~mm}^{-1}$.

(a)

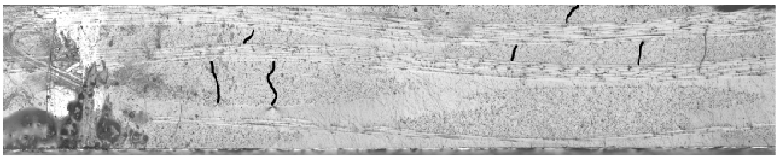

(c)

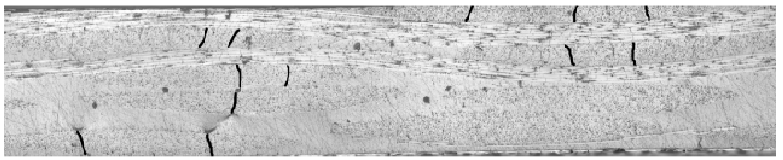

(e)

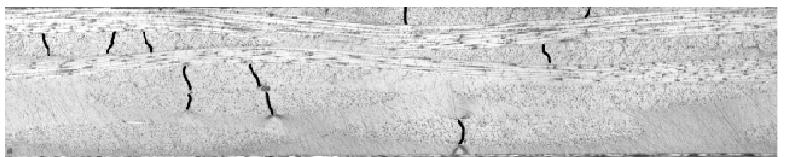

(a-e) Optical micrographs

(f) Numerical results
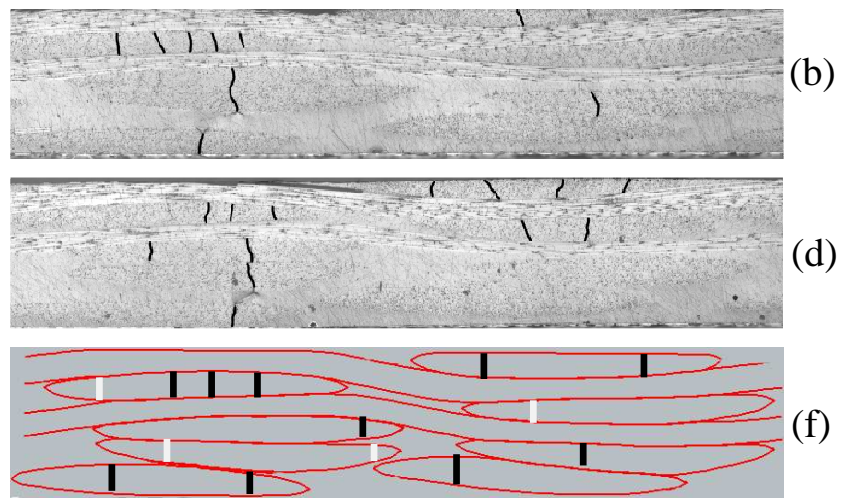

Figure 18: Comparison between crack locations (a-e) observed experimentally on the edge of the specimen and (f) obtained numerically for a crack density $\rho_{c}=0.18 \mathrm{~mm}^{-1}$. 
(a)

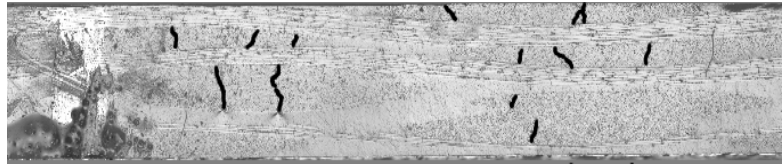

(c)

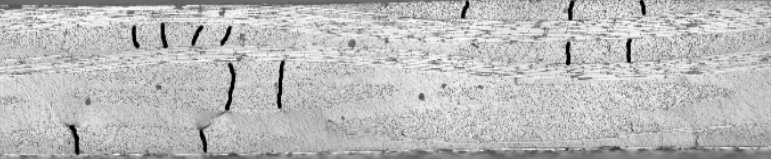

(e)

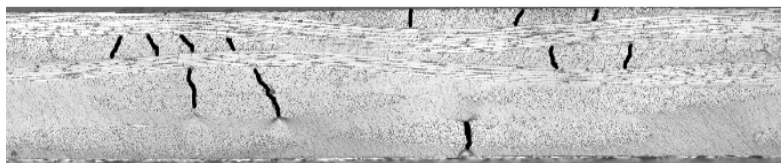

(a-e) Optical micrographs

(f) Numerical results

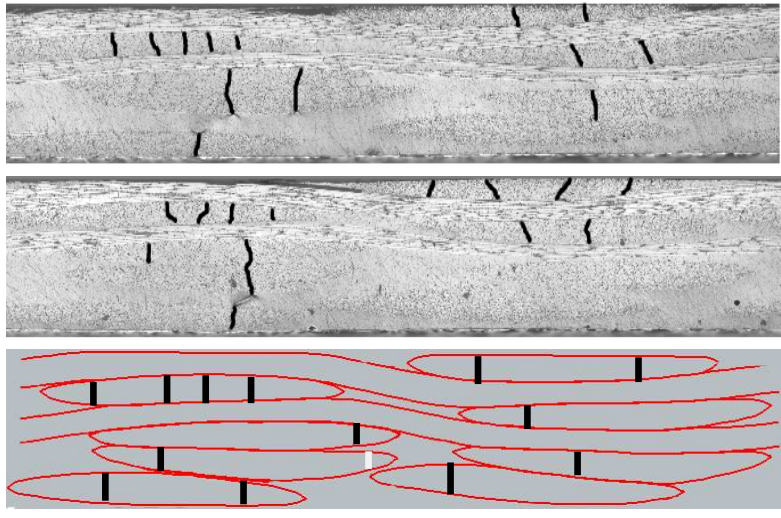

(b)

Figure 19: Comparison between crack locations (a-e) observed experimentally on the edge of the specimen and (f) obtained numerically for a crack density $\rho_{c}=0.22 \mathrm{~mm}^{-1}$. 
Table 1: Location of the crack center $\left(x_{c}, y_{c}, z_{c}\right)$, crack initiation length $\left(d_{c}^{*}\right)$, debond initiation length $\left(\mu_{c}^{*}\right)$ and initiation strain $\left(\epsilon_{c}\right)$ obtained for the 14 cracks under investigation using the method described in Ref. [24]

\begin{tabular}{|c|c|c|c|c|c|c|c|c|c|c|c|c|c|c|}
\hline Crack & 1 & 2 & 3 & 4 & 5 & 6 & 7 & 8 & 9 & 10 & 11 & 12 & 13 & 14 \\
\hline$x_{c}(\mathrm{~mm})$ & 0.65 & 3.31 & 8.08 & 2.05 & 4.8 & 8.82 & 1.82 & 4.3 & 0.2 & 0.78 & 3.5 & 5.4 & 7.89 & 8.82 \\
\hline$y_{c}(\mathrm{~mm})$ & 8.9 & 6.42 & 1.53 & 6.23 & 8.29 & 2.82 & 6.62 & 7.9 & 7.6 & 3.95 & 9.4 & 2.66 & 4.85 & 4.0 \\
\hline$z_{c}(\mathrm{~mm})$ & 0.11 & 0.37 & 0.19 & 0.43 & 0.48 & 0.5 & 0.74 & 1.01 & 1.22 & 1.26 & 1.51 & 1.57 & 1.20 & 1.24 \\
\hline$d_{c}^{*}(\mathrm{~mm})$ & 4.29 & 3.4 & 1.63 & 0.74 & 7.8 & 0.84 & 0.84 & 8.73 & 6.46 & 0.84 & 3.4 & 6.26 & 2.02 & 1.92 \\
\hline$\mu_{c}(\mathrm{~mm})$ & 0.033 & 0.063 & 0.066 & 0.021 & 0.02 & 0. & 0.02 & 0.02 & 0.036 & 0.02 & 0.066 & 0.04 & 0.064 & 0.056 \\
\hline$\epsilon_{c}\left(\times 10^{-3}\right)$ & 9.34 & 6.8 & 6.58 & 8.82 & 9.05 & 9.8 & 7.72 & 10.1 & 7.92 & 8.10 & 8.04 & 8.71 & 8.37 & 7.56 \\
\hline
\end{tabular}

Table 2: Strain $(\epsilon)$ level, crack $\left(d_{c}\right)$ and debond $\left(\mu_{c}\right)$ lengths obtained taking into account the coupling between close cracks.

\begin{tabular}{|c|c|c|c|c|c|c|c|c|c|c|c|c|}
\hline Coupling no. & \multicolumn{2}{|c|}{1} & \multicolumn{2}{|c|}{2} & \multicolumn{2}{c|}{3} & \multicolumn{3}{c|}{4} & \multicolumn{2}{c|}{5} & \multicolumn{2}{c|}{6} \\
\hline Crack no. & 4 & 7 & 3 & 6 & 5 & 8 & 14 & 9 & 11 & 12 & 14 & 13 \\
\hline$\epsilon\left(\times 10^{-3}\right)$ & \multicolumn{2}{|c|}{8.19} & \multicolumn{2}{|c|}{7.63} & \multicolumn{2}{|c|}{9.05} & \multicolumn{2}{|c|}{9.32} & \multicolumn{2}{c|}{8.90} & \multicolumn{2}{c|}{9.55} \\
\hline$d_{c}(\mathrm{~mm})$ & 0.84 & 0.43 & 5.62 & 0.25 & 8.76 & 0.4 & 7.45 & 1.65 & 5.63 & 6.13 & 7.7 & 2.35 \\
\hline$\mu_{c}(\mathrm{~mm})$ & 0.02 & 0 & 0.066 & 0 & 0.02 & 0 & 0.056 & 0 & 0.066 & 0 & 0.056 & 0.05 \\
\hline
\end{tabular}

Table 3: Young's modulus $\left(E_{11}\right)$ and Poisson's ratio $\left(\nu_{12}\right)$ obtained experimentally and numerically by mesomacro homogenization at the four crack density levels measured experimentally.

\begin{tabular}{|c|c|c|c|c|}
\hline$\rho_{c}\left(\mathrm{~mm}^{-1}\right)$ & 0.0941 & 0.1304 & 0.1774 & 0.2202 \\
\hline$\rho_{\mu}\left(\mathrm{mm}^{-1}\right)$ & 0.0379 & 0.0722 & 0.1002 & 0.1267 \\
\hline$E_{11}(\mathrm{GPa})$ Numerical & 20.66 & 20.54 & 20.42 & 20.24 \\
\hline$E_{11}(\mathrm{GPa})$ Experimental & {$[20.7-21.4]$} & {$[20.3-20.8]$} & {$[20.2-20.8]$} & {$[20.1-20.6]$} \\
\hline$\nu_{12}$ Numerical & 0.125 & 0.123 & 0.122 & 0.119 \\
\hline$\nu_{12}$ Experimental & {$[0.119-0.131]$} & {$[0.117-0.131]$} & {$[0.115-0.125]$} & {$[0.113-0.123]$} \\
\hline
\end{tabular}

